\title{
炔酰胺类缩合剂研究进展
}

\author{
刘涛 $a, b$ 许泗林 $c$ 赵军锋*,a,b \\ ( $a$ 西北工业大学化学制造研究院 西安 710072) \\ ( $b$ 江西师范大学化学化工学院 南昌 330022) \\ (c 许昌学院数理学院 河南许昌 461000)
}

\begin{abstract}
摘要 缩合剂是指用于促成羒酸与胺或者醇直接缩合构建酰胺键或酯键的一类试剂的总称. 由于酰胺和酯的重要性, 缩合剂的开发成为了学术界与工业界广泛关注的一个重要研究方向. 多肽合成就是 $\alpha$-氨基酸在缩合剂的作用下反复形 成酰胺键的过程，因此，缩合剂在多肽合成中发挥着至关重要的作用. 当前多肽合成所使用的试剂和技术大多是 20 世 纪 $50 \sim 80$ 年代发展起来的, 这些试剂和技术的天生弊端逐渐显现出来. 比如传统多肽缩合剂过度活化 $\alpha$-氨基酸而诱发 的外消旋化和其它副反应导致的副产物成为药物多肽生产过程中一个极为关切的问题. 另外固相多肽合成的低原子经 济性给可持续发展带来了极大的挑战. 这些问题只能依靠原始创新的颠覆性技术和全新的缩合方法来解决. 我们课题 组致力于通过发展新试剂和新反应来解决多肽与蛋白质化学合成领域的难题. 本文系统介绍了我们发展的一种结构全 新的炔酰胺类缩合试剂及其在酰胺、酯、大环内酯、多肽、硫代多肽合成中的应用研究进展.
\end{abstract}

关键词 炔酰胺; 缩合剂; 酰胺键; 多肽合成; 酯键; 大环内酯; 硫代多肽

\section{Recent Advances in Ynamide Coupling Reagent}

\author{
Liu, Tao ${ }^{a, b} \quad \mathrm{Xu}$, Silin $^{c} \quad$ Zhao, Junfeng ${ }^{*, a, b}$ \\ ( ${ }^{a}$ Institute of Advanced Synthesis, Northwestern Polytechnical University, Xi'an 710072) \\ ( ${ }^{b}$ College of Chemistry and Chemical Engineering, Jiangxi Normal University, Nanchang 330022) \\ ( ${ }^{c}$ School of Science, Xuchang University, Xuchang, Henan 461000)
}

\begin{abstract}
Coupling or condensation reagents are compounds that can be used to promote the direct condensation of carboxylic acids with amines or alcohols to furnish amide or ester bond, respectively. Since their discovery, coupling reagents have been widely used in the manufacture of drugs, materials, cosmetics and other fine chemicals containing amide or ester bond. In particular, coupling reagent plays a crucial role in the chemical synthesis of peptides which involves the iterative amide bond formation between proteinogenic $\alpha$-amino acids. However, current peptide synthesis methods and strategies are mainly relied on the reagents and techniques developed in $1950 \sim 1980$ s, and are reaching a high standard and their inherent limits. For example, the impurities and racemization/epmimerization caused by over activation of conventional coupling reagents have become major concerns of peptide drug manufacture. Moreover, the poor atom economy of the solid phase peptide synthesis results in large amount of chemical waste, and thus posing formidable challenge to the sustainable development. Only disruptive innovations involving new reagents and novel condensation mechanism can solve the notorious issues that plague current peptide synthesis. In this context, our research group disclosed that ynamide could be used as a novel coupling reagent to promote amide and ester bond formation via the condensation of carboxylic acids with amines or alcohols. More importantly, ynamide coupling reagents could also be used for peptide bond formation in a racemization free manner. Herein, the discovery as well as the application of ynamide coupling reagent in the construction of amide and ester bonds is systematically summarized.
\end{abstract}

Keywords ynamide; coupling reagent; amide bond; peptide synthesis; ester bond; macrolactone; thiopeptide

酰胺键和酯键广泛存在于自然界与人工合成的化 合物中, 其中酰胺键不但是自然界中最重要的化学键之
一, 也是有机合成化学最基本的化学键之一. 据统计约 有四分之一的上市药物和三分之一的候选药物含有酰

* Corresponding author. E-mail: zhaojf@jxnu.edu.cn

Received November 16, 2020; revised December 11, 2020; published online December 24, 2020.

Project supported by the National Natural Science Foundation of China (Nos. 21778025, 91853114)

国家自然科学基金(Nos. 21778025, 91853114)资助项目. 
胺键, 六分之一的有机化学反应涉及到酰胺键的形成 ${ }^{[1]}$. 同时酰胺键的形成反应是药物合成过程中应用最广泛 的有机化学反应 ${ }^{[2]}$. 多肽和蛋白质更是由若干天然 $\alpha$-氨 基酸通过酰胺键(肽键)有序连接而形成的具有重要功能 活性的分子. 因此, 酰胺键的形成是多肽和蛋白质合成 过程中最基本的化学反应. 由于酰胺键的重要性, 其构 建方法受到了化学家的广泛关注, 截止目前, 已经有上 百种酰胺键构建方法被开发出来 ${ }^{[3]}$. 但能够用于多肽合 成的方法非常有限, 这主要是因为肽键的构建需要用到 光学纯的手性原料砌块, 而这些手性原料大都难以获 得, 导致肽键形成的步骤冗长, 成本高昂. 由于天然 $\alpha$ 氨基酸是最便宜易得的手性原料, 相信在今后相当长的 时间内， $\alpha$-氨基酸在缩合剂的作用下直接缩合将仍然是 形成肽键的最稳健、方便和经济的方法[3a-3b,3g]. 因此, 多 肽缩合剂的性能仍将是制约多肽合成效率的关键因素.

由于多肽药物具有特异性强、副作用小和体内残留 低等诸多优点, 20 世纪中期, 具有重要生物活性的内源 性多肽及其衍生物受到了药物化学家的极大关注, 科学 家们相继开发出了一些多肽药物. 但是, 由于多肽药物 存在着透膜性差、无法口服及体内稳定性差等方面的先 天不足, 其地位逐渐被小分子药物取代了. 最近二三十 年来, 由于药物制剂技术和转运技术的快速发展和小分 子化合物成药性越来越低等原因, 多肽药物重新回到了 全球各大制药公司的视野中来, 多肽药物研发迎来了一 个快速复兴阶段 ${ }^{[4]}$. 截止目前, 全球已经有 70 多种多肽 药物相继上市, 其中不乏有格拉替雷和利拉鲁肽等 “重 磅炸弹” 级别的品种. 但是, 与小分子药物相比, 多肽药 物的化学合成涉及更长的路线和更加复杂的工艺, 因此 多肽药物一般都非常昂贵. 要想让多肽药物更好地造福 人类社会, 必须发展出颠覆性的多肽合成技术, 以保证 能够在合理的低成本条件下生产高纯度的多肽药物.

\section{1 缩合剂研究背景}

多肽合成的历史就是缩合剂与保护基的发展历程. 缩合剂可以在温和的条件下与羧酸发生反应(活化羧酸), 生成无需分离的高活性物种, 进而与胺发生氨解反应, 生成目标酰胺(Scheme 1). 由于缩合剂介导的酰胺键形 成方法不需预先制备酰卤、酸酐和活化酯等羧酸活化中 间体, 不仅简化了合成步骤, 而且还可以有效避免高活 性中间体分离纯化以及存放过程中产生的一些副反应. 然而缩合剂开发的 “窗口” 很窄, 这是因为如果缩合剂活 性不高, 将达不到活化羧酸的目的; 相反, 如果缩合剂活 性过高, 则会造成羧酸 $\alpha$-手性中心的外消旋化和其它副 反应的发生. 多肽缩合剂的开发始于 20 世纪 50 年代, 到 目前为止已经有上百种缩合剂问世[[3a-3b,3g].

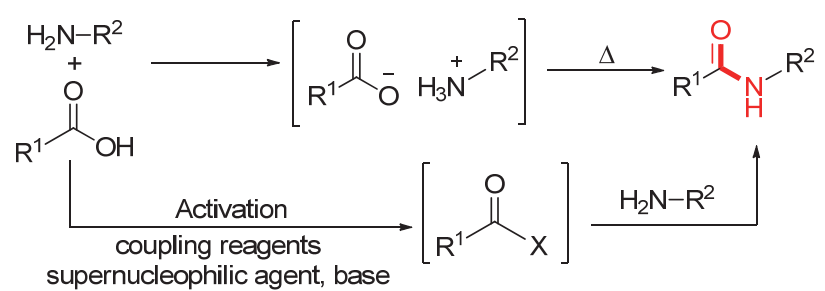

图式 1 羧酸与胺缩合构建酰胺键

Scheme 1 Amide bond formation from condensation of carboxylic acid and amine

$N, N^{\prime}$-二环己基碳二亚胺(DCC)是由 Sheehan 等 ${ }^{[5]}$ 于 1955 年开发出来的第一个用于多肽化学合成的碳二亚 胺型缩合剂，至今仍是酰胺与多肽合成中最常用的缩合 剂. 由于 $\mathrm{DCC}$ 缩合剂的副产物 $N, N^{\prime}$-二环已基脲(DCU) 在大多数溶剂中的溶解性都比较差，即便是通过离心、 柱层析的方式也很难将其从目标产物中完全除去. 为了 解决这个问题, 人们设计开发出一系列新型碳二亚胺类 缩合剂，例如 $N, N^{\prime}$-二异丙基碳二亚胺(DIC) ${ }^{[6]}$ 和 1-(3-二 甲氨基丙基)-3-乙基碳二亚胺盐酸盐(EDCI) ${ }^{[7]}$ 等，使副 产物的溶解性更好或使其可溶于水中, 这样可以方便地 除去副产物. 然而, 碳二亚胺型缩合剂在活化 $\alpha$-氨基酸 时，由于其活性过高，往往会导致氨基酸 $\alpha$-位的手性中 心发生较大程度的消旋(Scheme 2). 为了抑制外消旋化 副反应的发生，化学家设计开发了一系列的消旋抑制剂

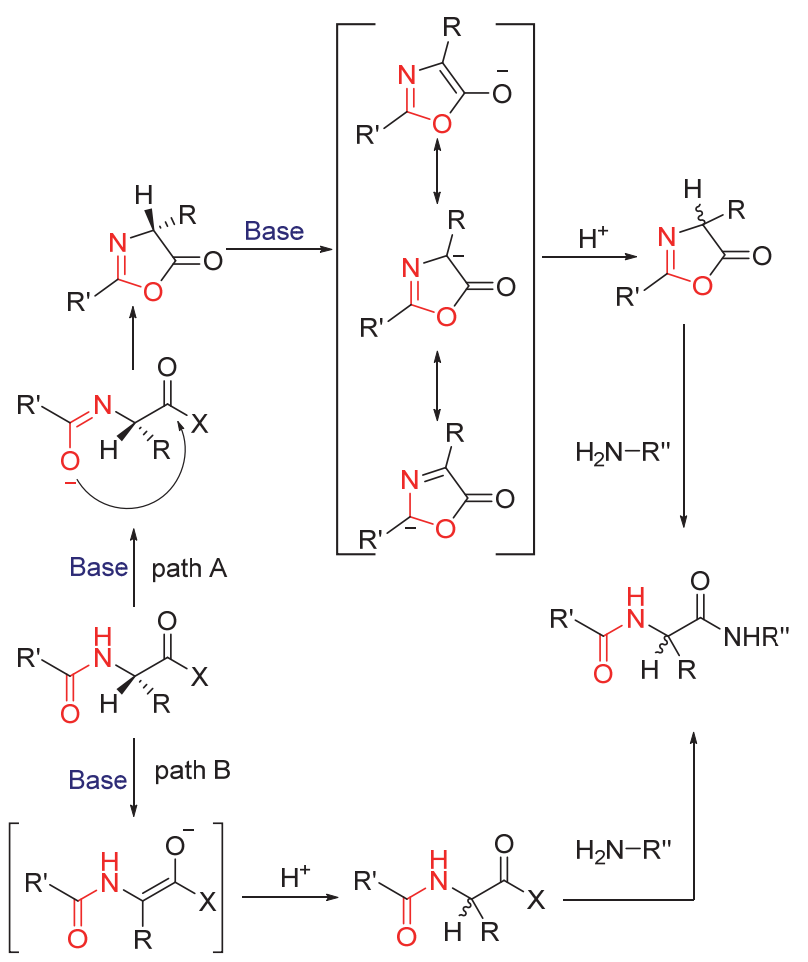

图式 2 多肽合成过程中消旋的反应机理

Scheme 2 Racemization mechanism during peptide bond formation 
(图 1)并将其与碳二亚胺型缩合剂联合使用. 消旋抑制 剂的使用不仅能够在一定程度上抑制消旋, 而且能够减 少其它副反应的发生, 使肽键形成的效率得以较大幅度 的提升.

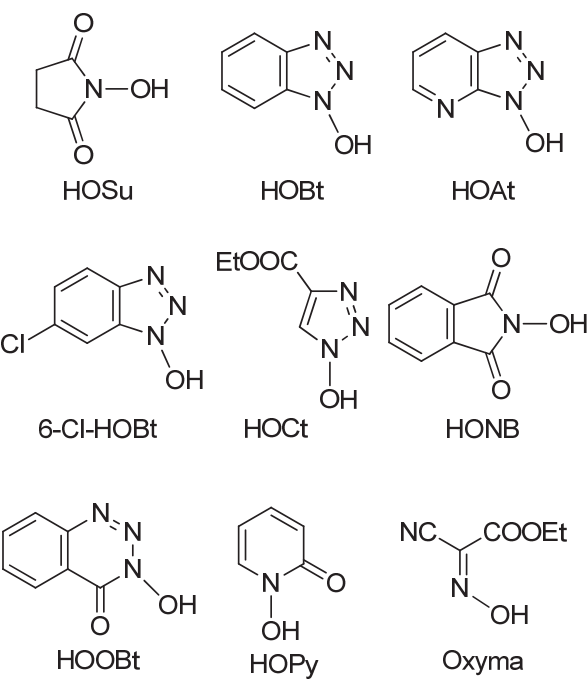

图 1 代表性消旋抑制剂

Figure 1 Representative racemization suppressors

随着消旋抑制剂被广泛地用于多肽合成, 为了使用 方便，科学家们将消旋抑制剂与缩合剂的功能设计到同 一个分子上, 开发出了一系列复合型双功能缩合剂, 如 鏻鎓盐类缩合剂、碳鎓盐类缩合剂以及其它类型的缩合 剂(图 2). 其中 $\mathrm{PyBOP}^{[8]} 、 \mathrm{HATU}^{[9]} 、 \mathrm{HBTU}^{[10]} 、 \mathrm{HCTU}^{[11]}$ 等缩合剂具有缩合效率高和消旋程度低等优点, 在多肽 合成领域得到了广泛使用. 但是, 基于 1-羟基苯并三唑 $(\mathrm{HOB} t)$ 结构衍生的消旋抑制剂在大规模使用过程中存 在着潜在的爆炸风险 ${ }^{[12]}$, 目前欧洲已经禁止了这类试 剂的使用 $(\mathrm{HOBt} \text { 及其衍生物被认定为第一类爆炸物 })^{[13]}$. 由于大多数缩合剂都是基于 $\mathrm{HOBt}$ 的结构进行设计的, 因此这些缩合剂也同样存在着爆炸的风险, 目前很多公 司已经不再使用基于 HOBt 结构的缩合剂 ${ }^{[14]}$. Oxyma ${ }^{[13]}$ 是最近开发出来的比较安全的消旋抑制剂, 有望成为 HOBt 的替代品. 基于 Oxyma 开发出来的碳鎓盐类缩合 剂 $\mathrm{COMU}^{[15]}$ 的缩合效率也比 $\mathrm{HOBt}$ 类缩合剂要高, 并且 消旋程度更低. 然而, 由于 COMU 在 $N, N^{\prime}$-二甲基甲酰 胺(DMF)中不稳定, 其在多肽固相合成中的应用仍然存 在着一些不确定性因素. 除了前面介绍的几类缩合剂以 外, 还有一些其它类型的缩合剂在多肽合成中均有一定

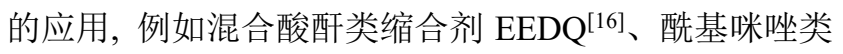
缩合剂 $\mathrm{CDI}^{[17]}$ 和三嗪类缩合剂 $\mathrm{DMTMM}^{[18]}$ 等.

我国的多肽与蛋白质化学合成研究曾经处于世界 前列, 1965 年我国科学家首次实现了结晶牛胰岛素的全<smiles>CCCOC1C=Cc2ccccc2N1C(=O)OCC</smiles>

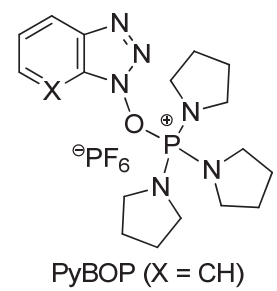
PYAOP $(X=N)$<smiles>[X]c1cccc2c([O-])n(C(N(C)C)=[N+](C)P)nc12</smiles>
HATU $(X=N)$
$\operatorname{HBTU}(\mathrm{X}=\mathrm{CH})$<smiles></smiles>

DEPBT<smiles>CCOC(=O)/C=C\N(C)C(O/N=C(\N)C(=O)OC)N1CCCCC1</smiles>

图 2 代表性缩合剂

Figure 2 Representative coupling reagents

合成 ${ }^{[19]}$. 参与结晶牛胰岛素合成的老一代科学家如徐 杰诚 ${ }^{[20]}$ 和叶蕴华 ${ }^{[21]}$ 等开发了一批多肽缩合剂, 在多肽 合成领域产生了重要的影响. 此后, 由于种种原因, 我 国的多肽与蛋白质化学合成研究经历了一段低迷时期. 近 10 年来, 我国在该领域的研究进入了一个快速复兴 的阶段. 其中, 刘否等 ${ }^{[22]}$ 开发的基于多肽酰肼的自然化 学连接法, 通过现场生成的多肽硫酯, 解决了自然化学 连接法中多肽硫酯合成的瓶颈问题. 李学臣等 ${ }^{[23]}$ 另辟 蹊径, 成功实现了基于 $\mathrm{Ser} / \mathrm{Thr}$ 的自然化学连接法, 突破 了多肽天然化学连接法必须使用半胱氨酸作为连接位 点的局限性. 我国科学家在蛋白质翻译后修饰 ${ }^{[24]}$ 及多 肽精准化学修饰研究领域也取得了一些重要的研究进 展 ${ }^{[25]}$. 但是, 除了钦传光等 ${ }^{[26]}$ 发展的基于液相载体的多 肽液相合成方法和张弛等 ${ }^{[27]}$ 利用高价碘试剂与三苯基 膦的组合来促成肽键形成外, 目前国内学者对于短链多 肽的合成和肽键形成方法的研究相对较少.

蛋白质的化学合成主要依托两大技术: 固相多肽合

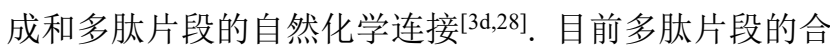
成主要是通过 Merrifield ${ }^{[29]}$ 于 1963 年发明的固相多肽合 成技术来实现的，由于省去了中间体的纯化和分离过 程，该方法将多肽合成的时间大大缩短，而且使很多以 前难以想象的多肽合成任务得以实现. 固相多肽合成技 术极大地推动了生命科学和化学学科的快速发展, 将固 相多肽合成与自动合成仪结合起来, 人们已经实现了多 肽合成的自动化. 固相多肽合成看起来好像已经是一种 “成熟的技术”，其实不然，虽然固相多肽合成技术对科 
学的发展产生了重大的推动作用, 但其仍然面临着诸多 棘手的问题，而且由于固相多肽合成技术的巨大影响， 这些问题经常被人所忽略. 固相多肽合成是以保护的氨 基酸为砌块, 在缩合剂的作用下反复形成肽键的过程, 需要不断重复 “保护” $\rightarrow$ “缩合” $\rightarrow$ “去保护” 三步操 作, 而理论上来讲只有 “缩合” 这一步是 “有实际价值 的”. 同时, 由于固相多肽合成是非均相反应, 而且只有 最后一步会进行纯化, 为了保证多肽合成的效率, 缩合 剂、添加剂和原料氨基酸总是大大过量(一般为 $4 \sim 10$ 倍 ${ }^{[30]}$. 为了形成一个酰胺键, 上百个原子被浪费掉了. 因此, 固相多肽合成的步骤经济学性和原子经济性都很 低 ${ }^{[31]}$, 不但导致多肽产品成本高昂, 而且给环境的可持 续发展造成很大的压力. 另外, 现在的多肽合成所使用 的缩合试剂大多是 20 世纪 $50 \sim 80$ 年代开发出来的, 这 些缩合剂在促成肽键形成时会诱发消旋以及其它由于 过度活化造成的副产物. 这些副产物往往与主产物的理 化性质很接近, 导致产物的分离纯化非常困难, 纯化成 本高昂. 因此, 当前的多肽合成技术已经达到了其瓶颈, 无法满足日益突出的可持续发展战略需求以及精准医 疗对多肽药物纯度的高标准要求(特别是手性纯度和杂 质含量的要求). 如何高效、高原子经济性地合成多肽仍 然是一个科学难题. 要想彻底解决这些困扰多肽合成的 问题, 必须要从基础研究的层面发展原始创新的颠覆性 技术, 才有望实现高原子经济性、高纯度的多肽化学合 成. 从而改变多肽原料药生产成本高昂及原子浪费严重 的现状. 我们课题组致力于通过发展有机化学新反应和 新试剂来解决多肽和蛋白质化学合成所面临的根本化 学问题. 五年来, 我们围绕酰胺键的形成方法学取得了 一些进展 ${ }^{[32]}$. 其中我们发展的炔酰胺类缩合剂是一种 结构全新的缩合试剂, 本文将系统介绍炔酰胺类缩合剂 的发现、合成及其在酰胺、多肽、硫代多肽、酯、大环 内酯和硫羰基酯合成应用中的研究进展.

\section{2 炔酰胺类缩合剂的发现}

1955 年, 几乎与 Sheehan 报道 DCC 缩合剂的同时, Arens ${ }^{[33]}$ 发现乙基乙炔醚也可以作为缩合剂来促成羧酸 与胺缩合形成酰胺(Scheme 3, path a). 这一缩合剂分子 量小, 结构简单, 副产物是乙酸乙酯, 是一种非常理想 的缩合试剂. 但是这种缩合剂本身热稳定性差, 对空气 中的水很敏感, 活化羧酸时的反应活性低, 需要使用 录、钉等过渡金属催化剂[ ${ }^{[34]}$, 而且当羧酸的 $\alpha$-位有手性 时会发生外消旋化. 为了获得性能更好的炔类缩合剂, Viehe 等 ${ }^{[35]}$ 于 1964 年将炔醚中的氧原子换成氮原子发展 了一种炔胺类缩合试剂(Scheme 3, path b). 虽然炔胺的 活性相对于炔醚得到了显著的提高, 但是炔胺类缩合剂
热稳定性更差, 对空气中的水更加敏感, 难以制备, 操 作困难且不易保存, 更为糟糕的是其在促成肽键形成时 会发生严重的外消旋化. 1978 年, Gais ${ }^{[36]}$ 和 Neuenschwander 等 ${ }^{[37]}$ 对炔胺的结构进行了改造(Scheme 3, path c), 在炔胺的另外一侧引入了吸电子的乙酰基, 试图利 用 “推-拉电子效应” 策略来解决炔胺类缩合剂的问题. 遗憾的是虽然这种策略在提升炔胺的稳定性上发挥了 一定的作用，但是其严重的消旋问题仍然未能得到解 决. 因此, 炔烃类缩合剂由于稳定性差、制备困难、使 用条件苛刻及诱发严重的消旋等诸多问题最终被多肽 合成领域彻底放弃.

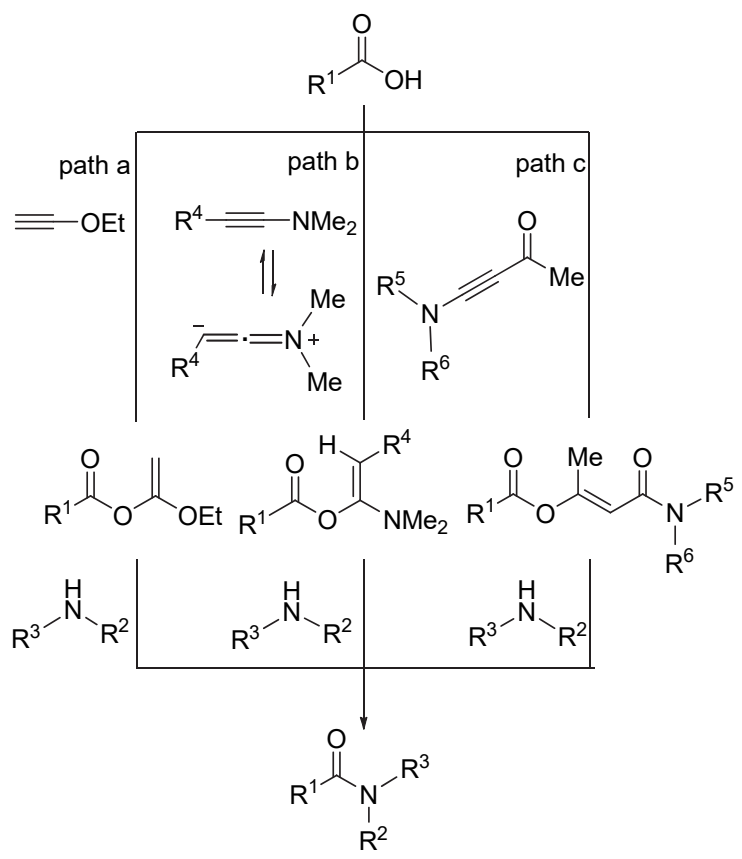

图式 3 炔烃类缩合剂介导的酰胺键形成

Scheme 3 Alkyne coupling reagents mediated amide bond formation

我们认为炔胺类缩合剂造成的严重外消旋化应该 归结于其自身的碱性会促使其从羧基 $\alpha$-位的手性碳原 子上瞳取氢原子, 从而诱发 $\alpha$-手性中心的消旋. 因此, 我们提出在炔胺的氮原子上引入一个吸电子基团, 通过 降低氮原子上的电子云密度, 不但可以达到稳定炔胺的 目的, 更为重要的是有望降低炔胺的碱性, 进而达到抑 制消旋的效果(Scheme 4). 然而, 这个看似简单的设想, 执行起来却充满了挑战性. 因为在氮原子上引入一个吸 电子基团后，该氮原子的供电子能力相对于炔胺会有所 降低, 其能否通过形成烯酮亚胺 1,3-偶极子型的共振结 构与羧酸进行加成反应是我们首要解决的问题; 其次, 该加成中间体是否能够与胺发生进一步的氨解反应也 是我们必须考虑的问题. 通过查阅相关文献，我们发现 炔酰胺就是这样的一类分子. 炔酰胺氮原子上的吸电子 
基团在平衡其稳定性和反应活性的关系中发挥着至关 重要的作用. 但自 1972 年 Viehe 等 ${ }^{[38]}$ 合成出第一个炔酰 胺后, 炔酰胺化学并未得到化学家的重视. 近 20 年来, 炔酰胺由于其特殊的结构和性能受到了有机化学家的 极大关注 ${ }^{[39]}$, 越来越多的炔酰胺参与的新反应逐步被 发掘出来, 炔酰胺已经成为了一种 “有机合成的万能工 具” ${ }^{[40]} .2012$ 年, Lam 等 ${ }^{[41]}$ 报道了炔酰胺与羧酸可以在 钯催化的条件下发生加成反应生成酰氧基烯酰胺. 2015 年，毕锡和等 ${ }^{[42]}$ 发现该反应在 $100{ }^{\circ} \mathrm{C}$ 的条件下不需要 使用过渡金属催化剂也能顺利进行. 虽然 Lam 和毕锡 和的反应条件比较苛刻, 但是他们的工作表明炔酰胺在 一定的条件下是可以与羧酸发生加成反应的, 坚定了我 们设计开发炔酰胺类缩合剂的信心.

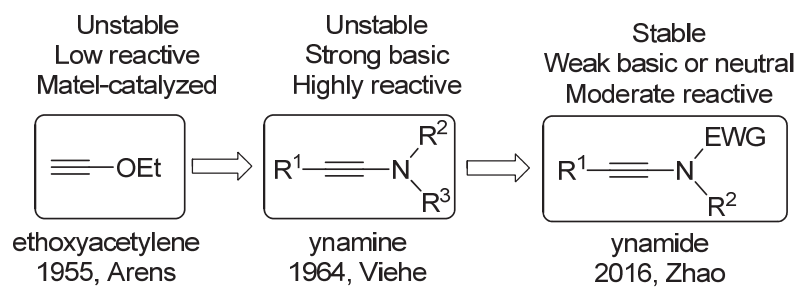

图式 4 炔酰胺类缩合剂的发现

Scheme 4 Discovery of ynamide coupling reagents

\section{3 炔酰胺介导的酰胺与多肽合成}

我们对炔酰胺与羧酸的加成反应 ${ }^{[39 \mathrm{c}]}$ 进行了系统深 入的条件篎选, 发现该反应受溶剂和炔酰胺自身结构的 影响非常大, 最后我们发现 $N$-甲基乙炔基甲磺酰胺 (MYMsA)和 $N$-甲基乙炔基对甲苯磺酰胺(MYTsA)在室 温条件下以二氯甲烷作为溶剂即可与羧酸快速地加成, 以近乎定量的收率得到相应的 $\alpha$-酰氧基烯酰胺(表 $1)^{[43]}$. 更重要的是 $\alpha$-酰氧基烯酰胺与胺能够进行自发的 氨解反应, 以几乎定量的收率得到目标酰胺. 这两步反 应均无需使用催化剂和添加剂等外加试剂. 值得注意的 是 $\alpha$-酰氧基烯酰胺(活化酯)是稳定的, 可以进行分离、 纯化和表征, 在冰箱中可保存长达半年以上的时间而不 会发生变质. 鉴于羧酸的活化与氨解这两步反应都可自 发进行而且非常高效, 为了操作方便, 我们采用了 “两 步一锅” 的策略, 即在第一步反应完成之后, 不需要分 离活化酯中间体, 直接向反应液中加入胺组分进行下一 步的反应, 即可得到目标酰胺, 简化了实际操作过程 $\left(\right.$ Scheme 5) ${ }^{[43]}$.

接下来我们对炔酰胺介导的羧酸与胺缩合的反应 适用性进行了系统的考察, 脂肪羧酸、芳基羧酸、杂环 羧酸和 $\alpha, \beta$-不饱和羧酸都能顺利地反应, 以良好和优秀 的收率获得目标酰胺. 由于亲核性增加, 一般情况下仲 胺氨解的速率高于伯胺. 虽然反应时间稍长, 但反应对
表 1 炔酰胺的构效关系 ${ }^{a}$

Table 1 Optimization of the ynamide

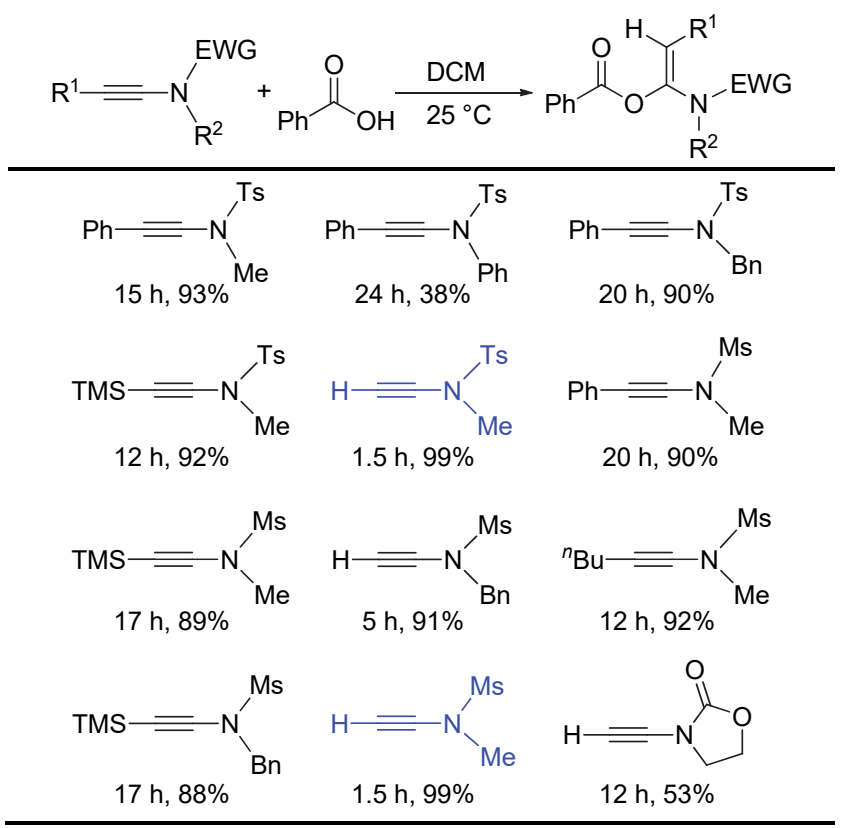

${ }^{a}$ Reaction conditions: ynamide $(0.2 \mathrm{mmol})$, carboxylic acid $(0.2 \mathrm{mmol})$, isolated yield.

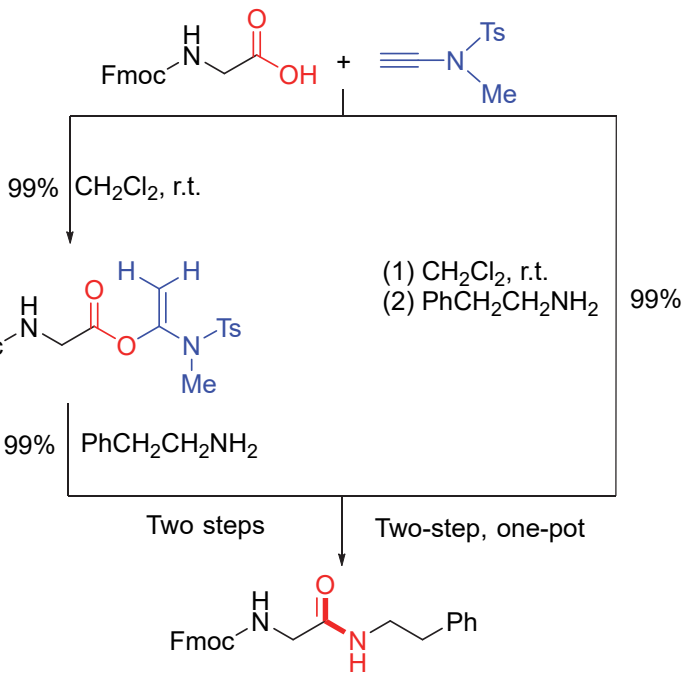

图式 5 炔酰胺介导的 “一锅法” 合成酰胺

Scheme 5 Ynamide-mediated "one-pot” synthesis of aimdes

于空间位阻大的胺底物也能够兼容. 另外, 即使是亲核 性较弱的 $O$-苠基羟胺也可以用作有效的亲核试剂. 当 使用多官能团的胺, 如 2-氨基乙醇和色胺作为胺时, 也 能获得优异的氨基选择性(表 2).

在成功实现了炔酰胺介导的酰胺键形成之后, 我们 希望把该方法应用于构建更具挑战性的肽键. 由于 $\alpha$-氨 基酸的氨基亲核性相对于普通脂肪胺要弱一些. 另外, $\alpha$-氨基酸的羧基在活化时存在着外消旋化的风险. 能否 在形成肽键时高效地保持 $\alpha$-氨基酸的手性是我们特别关 心的问题. 我们以比较容易消旋的 Fmoc- $L-\operatorname{Ser}\left(\mathrm{O}^{t} \mathrm{Bu}\right)-$ 
表 2 炔酰胺介导的酰胺合成 $a$

Table 2 Ynamide-mediated amide synthesis

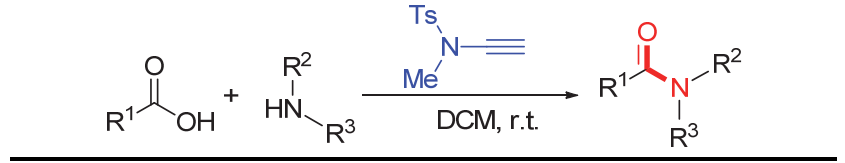<smiles>CC(=O)NCCc1ccccc1</smiles>

$98 \%, 30 \mathrm{~min} / 1.5 \mathrm{~h} \quad 99 \%, 10 \mathrm{~min} / 1 \mathrm{~h}$

$99 \%, 30 \mathrm{~min} / 12 \mathrm{~h}$<smiles>CC(C)(C)NC(=O)C12CC3CC(CC(C3)C1)C2</smiles>

$98 \%, \quad 30 \mathrm{~min} / 5 \mathrm{~h}$

$80 \%, 2 \mathrm{~h} / 24 \mathrm{~h}$

$99 \%, 10 \mathrm{~min} / 30 \mathrm{~min}$<smiles>CC(C)C(C)N(C(=O)C#Cc1ccccc1)C(C)C</smiles>

$76 \%, 10 \mathrm{~min} / 24 \mathrm{~h} \quad 95 \%, 10 \mathrm{~min} / 30 \mathrm{~min} \quad 90 \%, 10 \mathrm{~min} / 24 \mathrm{~h}$<smiles>O=C(C#Cc1ccccc1)NCCc1c[nH]c2ccccc12</smiles>

$99 \%, 10 \mathrm{~min} / 40 \mathrm{~min}$<smiles>O=C(NCCN1CCOCC1)c1ccc(Cl)cc1</smiles>

$98 \%, 4 \mathrm{~h} / 5 \mathrm{~h}$
${ }^{a}$ Reaction conditions: MYTsA ( $\left.0.2 \mathrm{mmol}\right)$, carboxylic acid $(0.2 \mathrm{mmol})$, amine $(0.22 \mathrm{mmol})$, reaction times for the first and second steps, respectively, isolated yield.

$\mathrm{OH}$ 为模板底物重点考察了肽键形成过程中手性 $\alpha$-氨基 酸发生外消旋化的情况. 从实验结果可以看出, 传统缩 合试剂在促成肽键形成时均会导致 Ser 残基发生不同程 度的消旋. 相反, 当使用炔酰胺 MYTsA 或 MYMsA 作 为缩合剂时, 氨基酸的手性能够得到完好的保持, 并以 几乎定量的收率得到目标产物(表 3). 虽然通过合理使 用传统缩合剂与缩合条件也有可能避免肽键形成时的 消旋 ${ }^{[44]}$, 但炔酰胺类缩合剂在避免消旋方面展现出了 显著的优越性.

之后, 我们进一步在二肽的合成中考察了炔酰胺类 缩合剂的普适性, 实验结果表明几乎所有的二肽都能以 优秀的产率获得. 天然 $\alpha$-氨基酸侧链的一些活泼官能团 如 $\mathrm{OH} 、 \mathrm{SH} 、 \mathrm{CONH}_{2}$ 、吲哚的 $\mathrm{NH}$ 等无需保护也能够兼 容, 具有较大位阻的氨基酸也可以顺利地反应并以优秀 的收率得到二肽. 更重要的是所有的二肽合成过程中都 没有检测到消旋的发生. 为了进一步证明炔酰胺作为缩 合剂在多肽合成中的潜在应用性, 我们采用 $2+3$ 片段 缩合策略合成了带保护基的 Leu-脑啡肽. 因此, 炔酰胺 类缩合剂不仅可以用于普通酰胺和二肽的合成, 而且能 够用来促成多肽片段连接(表 4). 相对于传统缩合剂, 炔 酰胺类缩合剂具有以下几个优势: 反应条件温和、操作 简单、无需额外的添加剂及催化剂, 更重要的是 $\alpha$-手性
表 3 各类缩合剂在多肽合成过程中外消旋化程度的研究对 比 $a$

Table 3 Comparative study of racemization/epimerization of peptide bond formation

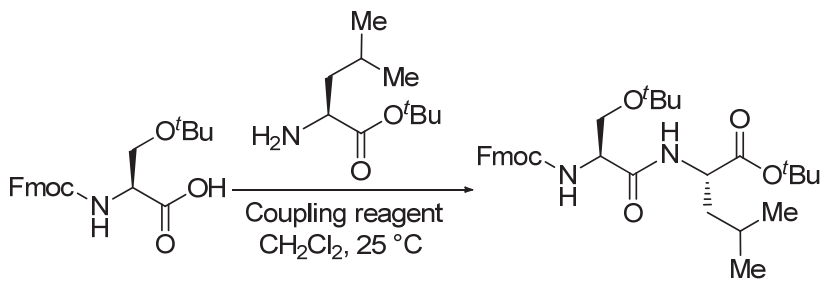

\begin{tabular}{cccccc}
\hline Entry & Coupling reagent & Additive & Time & Yield $^{b} \%$ & $d r^{c}$ \\
\hline 1 & HBTU & DIEA & $10 \mathrm{~min}$ & 90 & $82: 18$ \\
2 & HATU & DIEA & $10 \mathrm{~min}$ & 70 & $87: 13$ \\
3 & PyBop & DIEA & $10 \mathrm{~min}$ & 91 & $88: 12$ \\
4 & DEPBT & DIEA & $20 \mathrm{~min}$ & 61 & $99: 1$ \\
5 & DCC & - & $10 \mathrm{~min}$ & 98 & $91: 9$ \\
6 & MYMsA & - & $22 \mathrm{~h}$ & 99 & $>99: 1$ \\
7 & MYTsA & - & $22 \mathrm{~h}$ & 94 & $>99: 1$ \\
\hline
\end{tabular}

${ }^{a}$ Reaction conditions: Fmoc-Ser $\left({ }^{t} \mathrm{Bu}\right)-\mathrm{OH}(0.2 \mathrm{mmol}), \mathrm{H}-\mathrm{Leu}-\mathrm{O}^{t} \mathrm{Bu}(0.22$ $\mathrm{mmol})$, coupling reagent $(0.22 \mathrm{mmol})$, diisopropylethylamine (DIEA) $(0.4$ mmol). ${ }^{b}$ Isolated yield. ${ }^{c}$ Determined by HPLC analysis.

表 4 炔酰胺介导的多肽合成 ${ }^{a}$

Table 4 Ynamide-mediated peptide synthesis

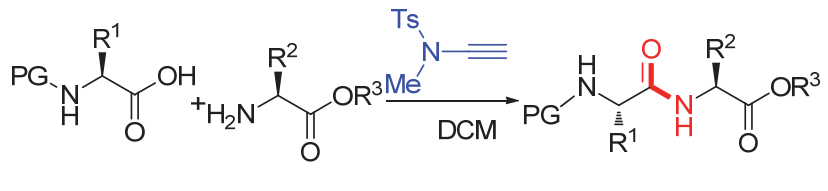<smiles>CCCCOC(=O)C(CC(C)C)NC(=O)[C@H](COCCC)NC(F)F</smiles>

$22 \mathrm{~h}, 99 \%,>99: 1 d r$<smiles>CCCCOC(=O)C(NC(=O)[C@H](CS)NOC(F)F)C(C)OCCC</smiles>

$22 \mathrm{~h}, 78 \%,>99: 1 d r$<smiles>CCCOC(=O)[C@H](NC(=O)C(CC(N)=O)NCC(C)C)C(C)O</smiles>

$20 \mathrm{~h}, 96 \%,>99: 1 d r$<smiles>CCCCC(=O)C(NC(=O)C(NC(F)F)C(C)O)C(C)O</smiles>

$20 \mathrm{~h}, 97 \%$, >99:1 dr<smiles>COC(=O)[C@H]1CCCN1C(=O)[C@@H](NC(=O)OCc1ccccc1)C(=O)O</smiles>

$12 \mathrm{~h}, 98 \%,>99: 1 d r$<smiles>CCCOC(=O)C(NC(=O)C(Cc1c[nH]c2ccccc12)NC(=O)OCc1ccccc1)C(C)O</smiles>

$18 \mathrm{~h}, 98 \%,>99: 1 d r$

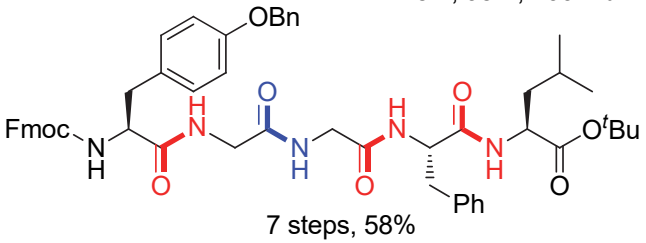

${ }^{a}$ Reaction conditions: acid partner $(0.2 \mathrm{mmol})$, amine partner $(0.22 \mathrm{mmol})$, MYTsA $(0.2 \mathrm{mmol})$, r.t., total reaction times for the two steps (the reaction time of the first step was less than $1 \mathrm{~h}$ ), isolated yield. 
羧酸在缩合的过程中不会发生外消旋化. 因此, 从环境 相容性和原子经济性的角度来讲, 炔酰胺是一种比较理 想的多肽缩合剂.

\section{4 炔酰胺介导的分子间酯化及大环内酯化}

酯键广泛地存在于医药、农药、高性能材料和其他 功能分子中, 也是众多天然产物和精细化学品及其中间 体的重要官能团. 因此, 用于形成酯键的酯化反应一直 以来都是学术界和工业界应用最广泛的有机反应之一. 常用的酯化方法有很多 ${ }^{[45]}$, 但是这些方法都有各自的 缺点, 如条件非常苛刻、反应效率差和工业规模化合成 困难等. 羧酸与醇或酚的缩合是合成酯类化合物最直接 的方法, 很多用于酸胺缩合的缩合剂都可以用来促成羧 酸与醇或酚的酯化反应. 然而, 传统缩合剂仍然存在着 诸多不足，如 $\alpha$-手性羧酸会发生严重的消旋、反应的副 产物及添加剂难以除去. 鉴于炔酰胺在其介导的酰胺键 形成反应中表现出的优异性能, 我们希望把炔酰胺缩合 剂的应用拓展到酯化反应中(Scheme 6).

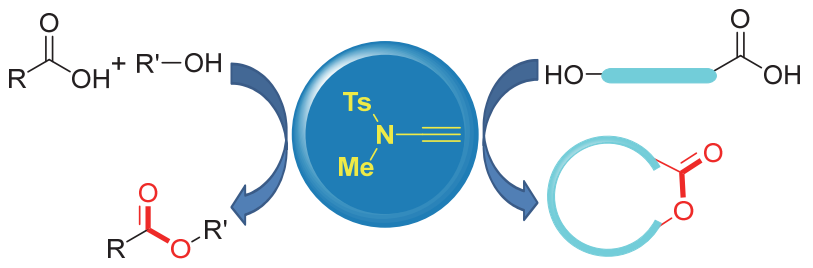

图式 6 炔酰胺介导的分子间酯化反应及大环内酯化反应

Scheme 6 Ynamide-mediated intermolecular esterification and macrolactonization

在炔酰胺介导的多肽合成的研究工作中, 我们发现 丝氨酸、苏氨酸和酪氨酸的侧链羟基在形成肽键时无需 保护也不会生成酯化副产物, 说明炔酰胺介导的酯化反 应在中性条件下是不会发生的. 但是, 我们在后续的研 究中发现用三氟乙醇或者甲醇作氨解反应的溶剂时, 观 察到少量的酯化副产物生成, 这些结果表明在一定条件 下炔酰胺介导的酯化反应是可以发生的. 因此我们考虑 通过使用酸碱催化剂来探索炔酰胺介导的羧酸与羟基 之间的脱水缩合反应. 通过系统、深入地优化反应条件, 我们发现分子间的酯化反应在酸性或者碱性条件下都 可以进行, 其中有机碱三乙胺为最优催化剂[46]. 与炔酰 胺介导的酸胺缩合反应类似, 我们可以采用一锅两步的 策略. 首先使羧酸与炔酰胺在二氯甲烷中发生加成反 应, 实现羧酸的活化. 然后将溶剂换为乙腈, 加入醇或 酚类化合物以及催化量的碱, 在常温下即可顺利地实现 羧酸的酯化反应. 该酯化反应对羧酸和醇、酚都有广泛 的耐受性，伯醇、仲醇以及各种取代的酚都能适用，脂 肪酸、芳香酸和 $\alpha, \beta$-不饱和羧酸都能够兼容, 产率都很 高. 值得注意的是具有手性的 $\alpha$-氨基酸也能顺利地反
应，虽然在三乙胺作为催化剂时观察到了少量的消旋, 但是使用大位阻的碱如 $N, N$-二异丙基乙胺(DIPEA)能够 完全避免外消旋化现象的发生(表 5).

表 5 炔酰胺介导的分子间酯化反应 ${ }^{a}$

Table 5 Ynamide-mediated intermolecular esterification

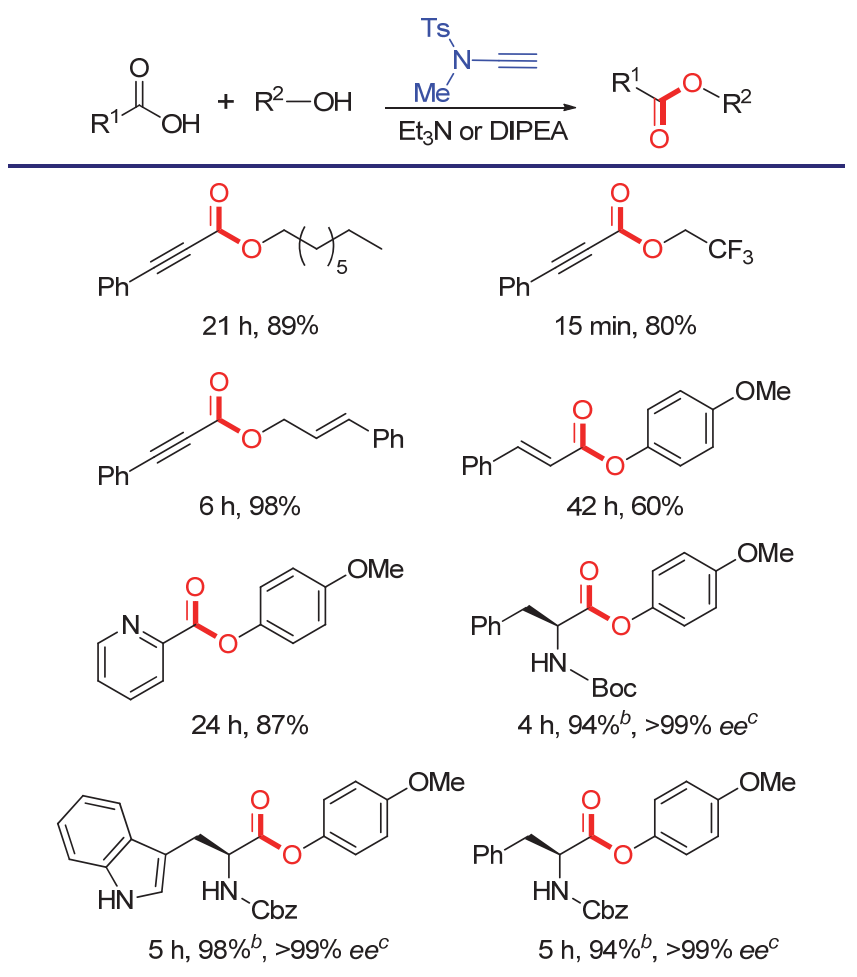

${ }^{a}$ Reaction conditions: (i) carboxylic acid $(0.2 \mathrm{mmol})$, MYTsA $(0.2 \mathrm{mmol})$, $\operatorname{DCM}(1 \mathrm{~mL})$; (ii) alcohol or phenol (0.24 mmol), $\mathrm{Et}_{3} \mathrm{~N}$ (0.04 mmol), MeCN (1 $\mathrm{mL})$, r.t., isolated yield. ${ }^{b}$ DIPEA $(0.04 \mathrm{mmol}),{ }^{c}$ Determined by HPLC analysis.

在实现了炔酰胺介导的分子间酯化反应之后，我们 将目光转向更具挑战性的大环内酯化反应. 大环内酯是 多种抗生素、药物、农用化学品和活性天然产物的重要 核心骨架. 由于大环内酯的重要性，化学家发展了一系 列策略来构建大环内酯 ${ }^{[47]}$. 其中通过直链羟基酸的分 子内酯化反应实现关环一直是有机化学家重点关注的 大环内酯化方法. 但由于这一过程的熵效应和焓效应对 关环反应都是不利的, 尤其是 $8 \sim 13$ 元环的中小环内酯, 经常会伴有比较严重的分子间聚合关环副反应. 常用的 几种大环内酯化人名试剂和人名反应都有其自身的不 足. 以大环内酯类天然产物全合成中应用最为广泛的 Yamaguchi-Yonemitsu 大环内酯化反应为例 ${ }^{[48]}$ ，由于该 方法需要使用过量的 $N, N$-二甲基-4-氨基吡啶(DMAP), 且经常需要在高温回流条件下进行反应, 当关环前体直 链羟基羧酸的 $\alpha$-位存在手性中心时, 经常会发生严重的 外消旋化. 另外, 当直链羟基羧酸为 $\alpha, \beta$-不饱和羧酸时, 与羧基共轭的碳碳双键在关环时会发生严重的顺反异 构化 ${ }^{[49]}$. 因此, 大环内酯化反应仍然是有机化学家所面 临的一个极具挑战性的课题. 
我们发现炔酰胺介导的分子间酯化反应的碱性条 件并不适用于大环内酯化反应，与之相反，酸性催化剂 有利于大环内酯化反应. 经过系统的反应条件优化, 我 们发现直链差基酸与炔酰胺加成可得羟基酸的 $\alpha$-酰氧 基烯酰胺衍生物(烯基活化酯), 这些羟基酸的活化酯在 $5 \mathrm{~mol} \%$ 的对甲苯磺酸一水合物 $\left(\mathrm{PTSA} \cdot \mathrm{H}_{2} \mathrm{O}\right)$ 的催化作用 下可以顺利进行关环, 以优秀的收率得到预期的大环内 酯产物. 由于第一步活化反应效率非常高, 这些活化酯 可以不经纯化而直接进行后续的酸催化关环反应，从而 提供了一种 “两步一锅” 的大环内酯化方法. 两步反应 都可以在室温的敞口容器中进行, 避免了传统大环内酯 化反应的高温、强碱性及严格的无水条件, 操作简便. 与传统大环内酯化反应需要在极低的底物浓度下进行 $\left(\leqslant 1 \mathrm{mmol} \cdot \mathrm{L}^{-1}\right)$ 不同, 炔酰胺介导的大环内酯化可以在 $5 \sim 100 \mathrm{mmol} \cdot \mathrm{L}^{-1}$ 的底物浓度下进行反应而不会显著地 产生二聚关环副产物. 这个优势在将来大环内酯的规模 化制备中可以节省大量的溶剂, 具有重要的经济价值. 用其它方法难以制备的 $8 \sim 13$ 元环的大环内酯也可以通 过该方法构建. 该方法在用于含有 $\alpha$-手性中心的直链羟 基酸和含有共轭烯烃的 $\alpha, \beta$-不饱和直链羟基酸时展现出 了显著的优越性, 可以完全避免其它大环内酯化策略中 常见的 $\alpha$-手性中心的外消旋化和碳碳双键的顺反异构 化. 此外, 该方法还适用于制备同时含有酯键和酰胺键 的大环内酯肽, 通过大环内酯化反应而非内酰胺化反应 作为最终的关环步骤, 为合成大环内酯肽提供了一种极 具吸引力的替代方法 $(\text { 表 } 6)^{[50]}$.

为了进一步展示该方法的应用潜力, 我们将其用于 大环内酯肽天然产物 Dehydroxy LI-F04a 核心骨架的构 建. Dehydroxy LI-F04a 是大环内酯肽类天然产物 LI-F 家 族的一个代表, 该家族分子含有一个由六个氨基酸形成 的大环内酯肽核心骨架. 理论上来讲, 该大环内酯肽可 以通过任意酰胺键或酯键的形成来关环. 但是, 由于线 性多肽片段在进行分子内酯化时充满了挑战, 而且有时 酯键在后续的肽键形成中会受到其它亲核试剂的进攻 而断开. 因此, 通过酯键的形成来关环的大环内酯化反 应成为构建大环内酯肽极具吸引力的备选方案. 大环内 酯肽类天然产物 Dehydroxy LI-F04a 就是这样的分子, Jolliffe 课题组 ${ }^{[51]}$ 曾经对 Dehydroxy LI-F04a 进行过深入 系统的研究, 他们发现关环位点 $D$-Ala 的绝对构型对其 生物活性至关重要, 该 $D$-Ala 残基的外消旋化会直接导 致其抗菌活性完全消失. 然而, 大多数大环内酯化策略 均会造成该 $D$-Ala 残基严重的外消旋化. 我们发现炔酰 胺缩合剂可以很好地解决这个问题, 与传统大环内酯化 方法相比, 炔酰胺介导的大环内酯化反应的优势非常明 显, 反应速度快、收率高、条件温和、操作方便, 更重
表 6 炔酰胺介导的大环内酯化反应 ${ }^{a}$

Table 6 Ynamide-mediated macrolactonization
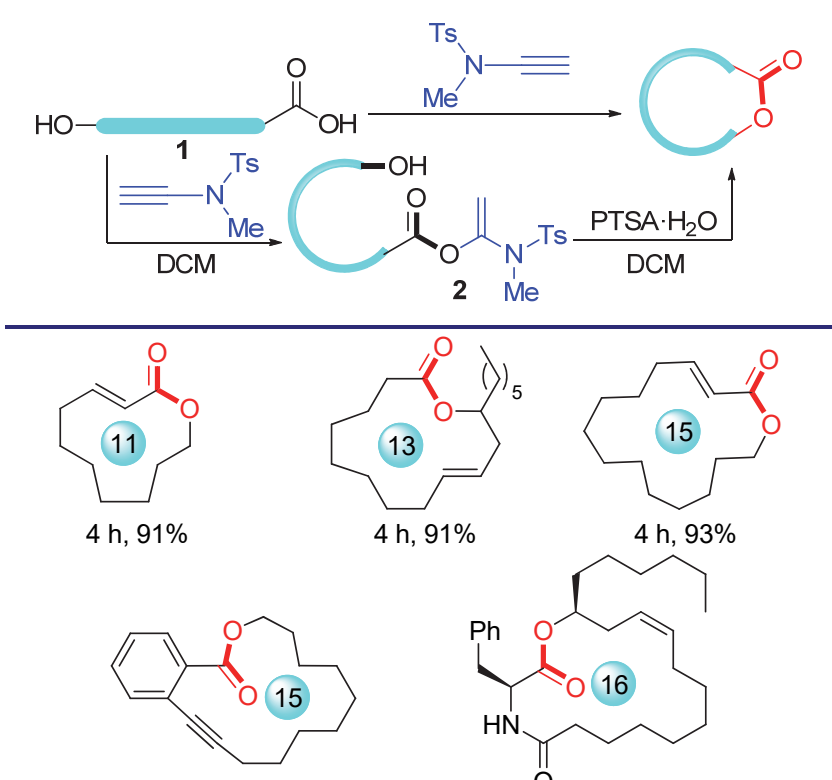

$3 \mathrm{~h}, 99 \%$

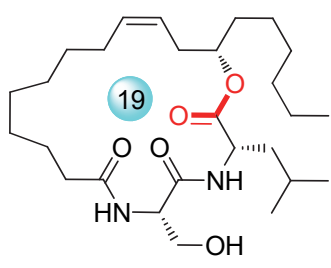

$4 \mathrm{~h}, 67 \%$
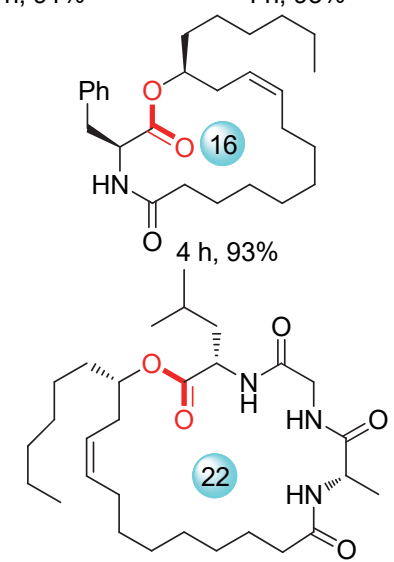

$10 \mathrm{~h}, 87 \%$
${ }^{a}$ Reaction conditions: (i) $1(0.1 \sim 0.4 \mathrm{mmol})$, MYTsA (1.1 equiv.), DCM $(1 \sim 2$ $\mathrm{mL})$, r.t., $1 \sim 24 \mathrm{~h}$; (ii) $2(0.1 \sim 0.4 \mathrm{mmol}), \mathrm{PTSA} \cdot \mathrm{H}_{2} \mathrm{O}(15 \mathrm{~mol} \%)$, r.t., $0.3 \sim 4$ $\mathrm{h}$, isolated yield.

要的是关环位点氨基酸残基的手性能够得到完好的保 持 $(d r>99: 1)$ (表 7). 以炔酰胺介导的大环内酯化反应 为关键步骤，我们高效地实现了大环内酯肽天然产物 Dehydroxy LI-F04a 的全合成.

\section{5 炔酰胺介导的硫代多肽合成}

自然界中的蛋白质和多肽在行使其生物功能时经 常需要进行种类繁多的翻译后修饰, 其中将蛋白质和多 肽主链骨架上的肽键羰基氧原子替换成硫原子而得到 硫代蛋白质和硫代多肽就是一种最新发现的翻译后修 饰方式 ${ }^{[52]}$. 将肽键羰基氧原子替换为硫原子是目前多 肽主链骨架修饰中造成其一级结构变化最小的一种修 饰方式. 虽然硫肽键修饰已经成为研究蛋白质功能、结 构、折叠及动力学的一种非常有用的化学生物学工 具 ${ }^{[53]}$, 但由于合成方法上的局限性, 其在蛋白质化学生 物学研究中的应用潜能还未被充分发掘出来. 目前合成 硫代酰胺的策略主要有两种，一种是酰胺羰基硫化法, 另一种是硫羰基化法. 第一种策略不但要用到恶臭剧毒 的硫化试剂, 而且由于其对多肽上的多个肽键没有选择 
表 7 大环内酯化方法对比 ${ }^{a}$

Table 7 Comparative study of macrolactonization methods

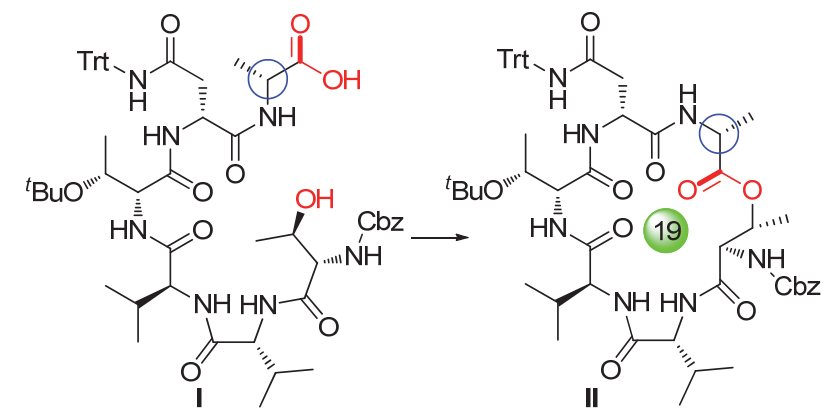

\begin{tabular}{|c|c|c|c|c|}
\hline Entry & Reaction conditions & II:II' ${ }^{b}$ & Yield $^{c} \%$ & $d r$ \\
\hline 1 & $\begin{array}{l}\mathrm{DCC}, \mathrm{DMAP}, \mathrm{CSA}, \mathrm{CHCl}_{3} \text {, } \\
\text { r.t., } 4 \mathrm{~h}\end{array}$ & $98: 2$ & 34 & $89: 11$ \\
\hline 2 & $\begin{array}{l}\text { EDCI, HOAT, DMAP, CH- } \\
\mathrm{Cl}_{3} \text {, r.t., } 4 \mathrm{~h}\end{array}$ & $69: 31$ & 13 & $37: 63$ \\
\hline 3 & $\begin{array}{l}\mathrm{HBTU}, \mathrm{DMAP}, \mathrm{CHCl}_{3} \text {, r.t., } 2 \\
\mathrm{~h}\end{array}$ & $90: 10$ & 20 & $23: 77$ \\
\hline 4 & $\begin{array}{l}\text { TBTU, HOAT, DMAP, } \mathrm{CH}_{2-} \\
\mathrm{Cl}_{2} \text {, r.t., } 1 \mathrm{~h}\end{array}$ & $>99: 1$ & 33 & $69: 31$ \\
\hline 5 & $\begin{array}{l}\mathrm{HATU}, \mathrm{DMAP}, \mathrm{CHCl}_{3} \text {, r.t., } \\
30 \mathrm{~min}\end{array}$ & $78: 22$ & 38 & $93: 7$ \\
\hline 6 & $\begin{array}{l}\text { PyBop, DMAP, } \mathrm{CH}_{2} \mathrm{Cl}_{2} \text {, r.t., } \\
2 \mathrm{~h}\end{array}$ & $46: 54$ & 12 & $27: 73$ \\
\hline 7 & $\begin{array}{l}\text { PySSPy, } \mathrm{PPh}_{3}, \quad \mathrm{MeCN}, \\
80{ }^{\circ} \mathrm{C}, 8 \mathrm{~h}\end{array}$ & $21: 79$ & 5 & $92: 8$ \\
\hline 8 & $\mathrm{PPh}_{3}$, DEAD, THF, r.t., $48 \mathrm{~h}$ & $>99: 1$ & 6 & $29: 71$ \\
\hline 9 & $\begin{array}{l}\text { 2-methyl-6-nitrobenzoic an- } \\
\text { hydride, DMAP, } \mathrm{NEt}_{3} \text {, tolu- } \\
\text { ene, } 25{ }^{\circ} \mathrm{C}\end{array}$ & nd & $(52)$ & $94: 6$ \\
\hline 10 & $\begin{array}{l}\text { MYTsA, PTSA } \cdot \mathrm{H}_{2} \mathrm{O}, \mathrm{CH}_{2}- \\
\mathrm{Cl}_{2} \text {, r.t., } 10 \mathrm{~min}\end{array}$ & $>99: 1$ & $87(92)$ & $>99: 1$ \\
\hline
\end{tabular}

${ }^{a}$ Reaction conditions: Seco-acid I $(0.005 \mathrm{mmol})$, solvent $(2 \mathrm{~mL})$, concentration $(2.5 \mathrm{mmol} / \mathrm{L}) .{ }^{b}$ Determined based on analytical HPLC of the crude reaction mixture, II' is diolide; ${ }^{c}$ HPLC yield of II using biphenyl as an internal standard; the isolated yield is reported in the parentheses.

性，因此不能用于多肽硫代酰胺化精准修饰. 第二种策 略需要预先制备硫羰基试剂, 由于硫羰基的 $\alpha$-氢具有较 强的酸性, 在构建硫肽键时硫羰基 $\alpha$-位手性中心更容易 发生外消旋化, 同时其较高的亲核性还会导致其他副反 应的发生 ${ }^{[54]}$. 因此, 在多肽和蛋白质主链骨架上精准地 引入硫代酰胺键修饰仍然面临着很大的挑战, 而这也是 制约硫肽键在蛋白质化学生物学研究领域中广泛应用 的瓶颈问题.

我们注意到单硫代羧酸在溶液中存在着硫羰基酸 和硫差基酸两种互变异构体的转化平衡, 该平衡移动方 向可以通过改变温度及溶剂等条件来调控. 早在 1973 年 Yoshio 课题组 ${ }^{[55]}$ 就发现硫代苯甲酸在不同添加剂条
件下可以选择性得到硫羰基化合物和硫酯化合物. Hoeeg-Jensen 研究组 ${ }^{[56]}$ 以 PyBOP 为缩合剂, 将单硫代羧酸 与胺缩合得到了硫代酰胺. 虽然该方法的选择性很差, 但为制备硫代酰胺提供了一种新的思路. 基于上述工作 的启发和炔酰胺缩合剂的作用机制，我们设想如果炔酰 胺缩合剂能够捕捉到单硫代着酸的硫羰基异构体得到 硫羰基活化酯的话，我们将有望获得一种新型的硫羰基 化试剂, 从而发展一种构建硫代酰胺的新方法(Scheme 7). 当向单硫代羧酸的二氯甲烷溶液中加入炔酰胺缩合 剂时, 我们确实得到了硫酯与硫羰基酯 $1: 1$ 的混合物. 经过系统的条件优化, 我们发现低温、非极性溶剂的反 应条件有利于生成硫羰基活化酯, 最终我们在 $-40{ }^{\circ} \mathrm{C}$ 的间二甲苯溶液中以大约 $2: 1$ 的选择性获得了硫羰基 酯, 这两种酯可以很容易地通过柱层析分开. 令我们高 兴的是硫羰基酯可以非常高效地与胺反应生成硫代酰 胺 ${ }^{[57]}$.

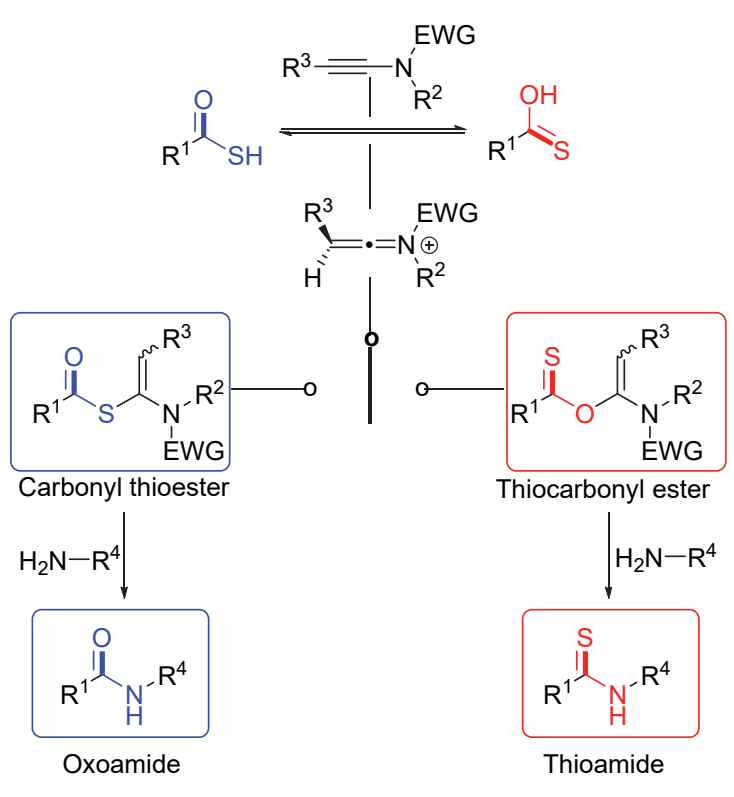

图式 7 炔酰胺介导的硫代酰胺合成

Scheme 7 Ynamide-mediated thioamide synthesis

因为氨基酸的单硫代羧酸衍生物很容易从天然氨 基酸制得, 因此我们尝试了 20 种天然氨基酸的硫酰化 试剂的制备. 实验结果表明, 19 种天然氨基酸(除了组氨 酸)都能够以较高的选择性得到相应的硫酰化试剂(表 8). 在硫酰化试剂的合成中，未保护的氨基酸侧链活泼 官能团如 $\mathrm{OH} 、 \mathrm{SH} 、 \mathrm{CONH}_{2}$ 、吲哚的 $\mathrm{NH}$ 对反应均不会 造成影响. 此外, 当用二氯甲烷作为氨解反应的溶剂时, 我们也观察到 $\beta$-位有 $\mathrm{sp}^{2}$ 杂化碳原子的氨基酸在形成硫 肽键时其 $\alpha$-位手性中心会发生少量外消旋化的现象，这 也从侧面印证了硫肽键的构建更具挑战性. 令人欣慰的 是这些少量的外消旋化可以通过使用 DMF 作溶剂来避 
免. 除了个别极易消旋的底物需要在 $0{ }^{\circ} \mathrm{C}$ 下来合成外, 大多数的硫代二肽都可在室温条件下无外消旋化地获 得(表 9). 除了一些硫代二肽的合成, 该方法还可以在多 肽片段中定点引入硫肽键, 实现模块化式的多肽精准硫 代酰胺化修饰. 利用这个方法, 我们实现了硫代脑啡肽
的精准硫代酰胺化修饰(Scheme 8)以及多硫代酰胺类天 然产物 Closthioamide 的全合成.

目前的多肽合成主要是通过 Merrifield 的固相多肽 合成技术来实现的，如果能够在固相多肽合成中定点的 引入硫肽键，将会为多肽的硫代酰胺化修饰提供一种更

表 8 选择性地合成硫酰化试剂 $a$

Table 8 Chemoselective synthesis of thioacylation reagents
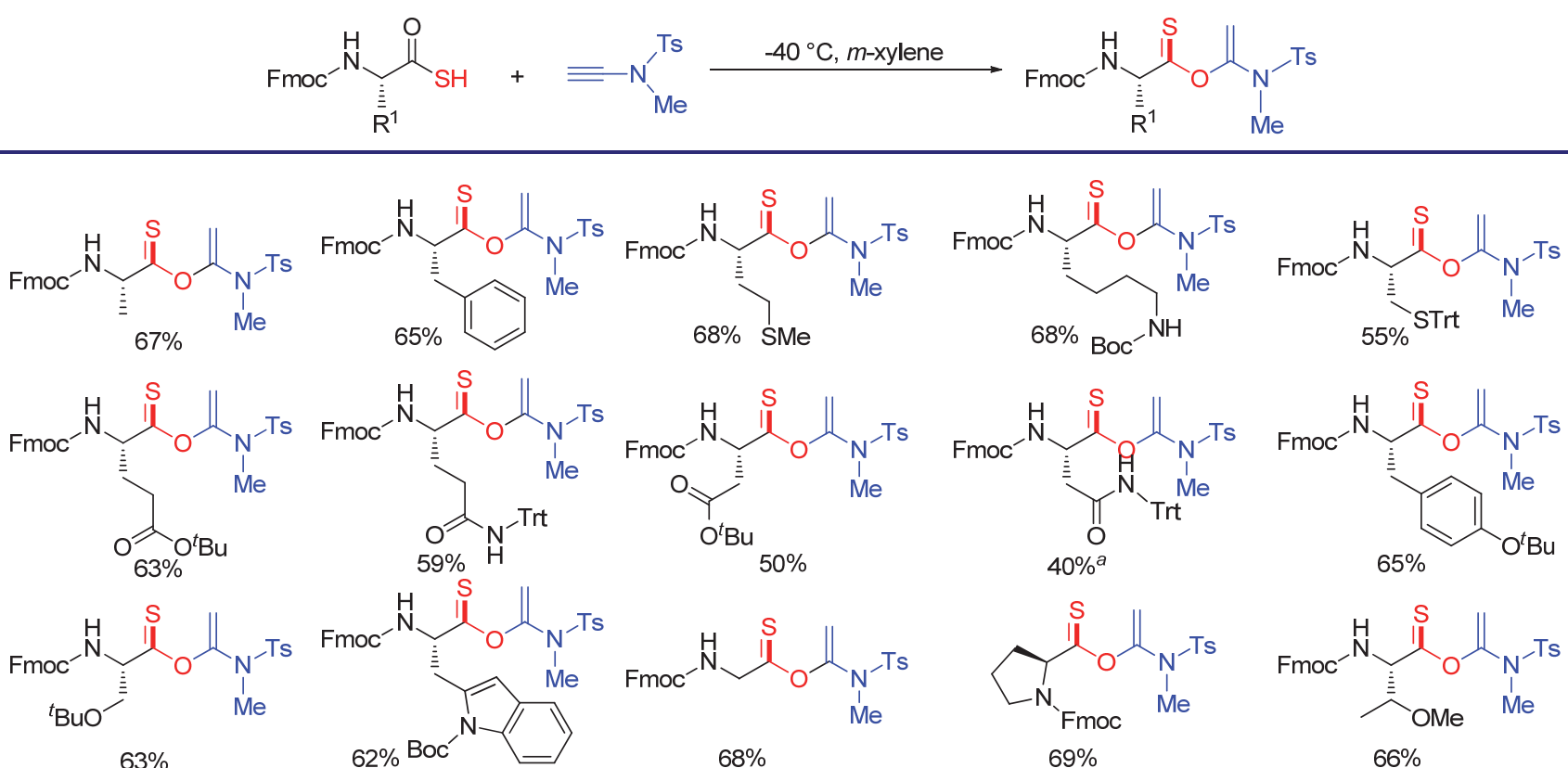
$63 \%$

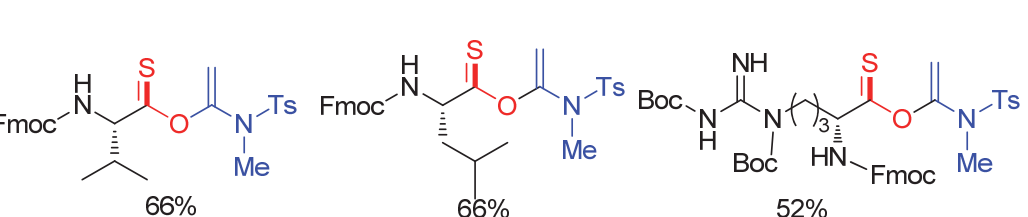<smiles>C=C(OC(=S)[C@H](Cc1cncn1C)NC(F)F)N(C)[Al]</smiles>

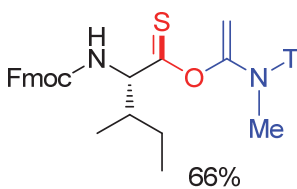
$66 \%$ $52 \%$

These reactions were carried out with amino acid $(0.15 \mathrm{mmol}, 1.5$ equiv. $)$ MYTsA $(0.1 \mathrm{mmol})$, and $m$-xylene $(1.0 \mathrm{~mL})$ at $-40{ }^{\circ} \mathrm{C}$ for $8 \mathrm{~h}$, isolated yield, NR $=$ no reaction. Fmoc $=$ fluorenylmethoxy, Boc $=$ tert -butoxycarbonyl, $\operatorname{Trt}=$ trityl.

表 9 炔酰胺介导的硫代多肽合成 ${ }^{a}$

Table 9 Ynamide-mediated thioamide substituted peptide synthesis

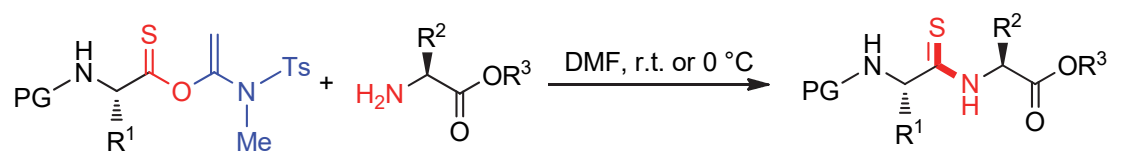<smiles>CCCCC(=O)N[C@@H](CC(C)C)C(=O)N[C@@H](C)C(=O)OCc1ccccc1</smiles>

$\mathrm{PG}=\mathrm{Cbz}, 96 \%, 5 \min d r>99: 1$ $\mathrm{PG}=\mathrm{Boc}, 99 \%, 5 \mathrm{~min} d r>99: 1$ $\mathrm{PG}=\mathrm{Fmoc}, 95 \%, 5 \mathrm{~min} d r>99: 1$<smiles>CCCCC(=O)OC(=O)[C@H](CC(C)C)NC(=S)[C@H](CCC(N)=O)NC(=O)O</smiles>

$92 \%, 1 \mathrm{~h}, d r>99: 1$<smiles>CCCCOc1ccc(C[C@H](NC(=O)OCc2ccccc2)C(=S)N[C@H](C(=O)OCCC)C(C)O)cc1</smiles>

$91 \%, 1 \mathrm{~h}, d r>99: 1$<smiles>CCCCOC(=O)[C@H](CC(C)C)NC(=S)[C@H](CO)NC(=O)OCc1ccccc1</smiles><smiles>COC(=O)[C@H](Cc1c[nH]c2ccccc12)NC(=S)[C@H](Cc1ccccc1)NC(=O)OCc1ccccc1</smiles>

$95 \%, 1 \mathrm{~h}, d r>99: 1$<smiles>CCCCOC(=O)[C@H](CC(N)=O)NC(=S)[C@H](Cc1ccccc1)NC(=O)O</smiles>

$94 \%, 1 \mathrm{~h}, d r>99: 1$<smiles>CCOC(=O)C[C@H](NC(=S)[C@@H](CCCCNC(=O)OC(C)(C)C)NC(=O)OC(C)(C)C)C(=O)OCC(C)(C)C</smiles>

95\%, $10 \mathrm{~min}, d r>99: 1$

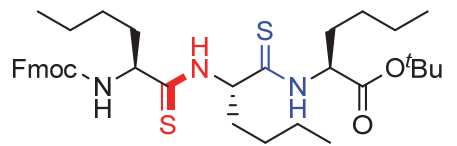

$91 \%, 3 \mathrm{~h}, d r>99: 1$

${ }^{a}$ Reaction conditions: thiocarbonylester $(0.3 \mathrm{mmol})$, amine coupling partner $(0.36 \mathrm{mmol})$, DMF $(2 \mathrm{~mL})$, isolated yield. 


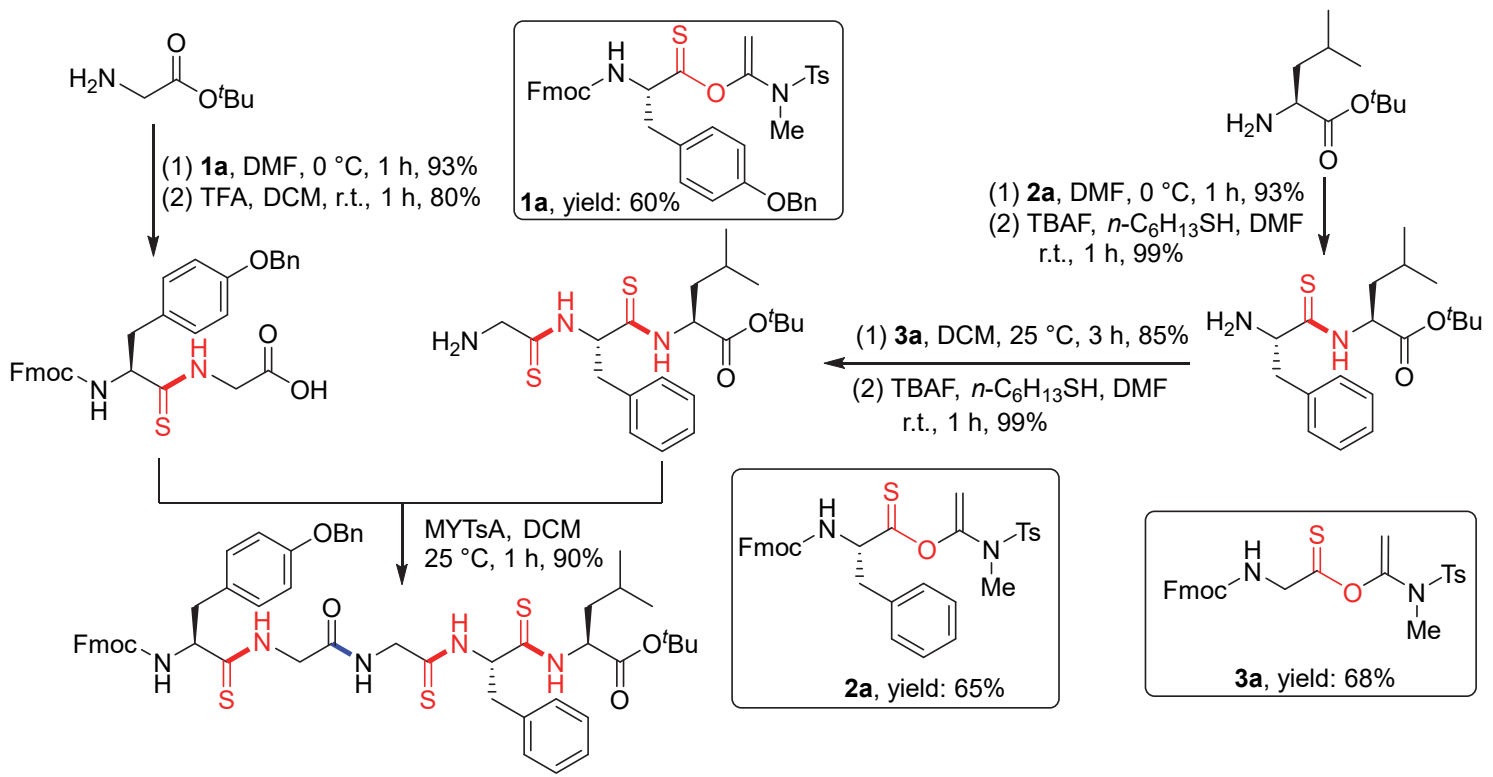

图式 8 硫代脑啡肽的合成

Scheme 8 Synthesis of trithioamide-substituted Leu-enkephalin

加便捷的方法. 目前能够在固相多肽合成中引入硫代酰 胺化修饰的硫羰基化试剂只有硫羰基苯并三唑类衍生 物 ${ }^{[58]}$, 然而该类硫炭化试剂的制备不但涉及剧毒恶臭 的硫化试剂的使用, 而且只适用于 15 种天然氨基酸的 硫羰基化修饰. 我们发现通过单硫代羒酸与炔酰胺缩合 剂加成制备得到的硫酰化试剂相对比较稳定, 可以进行 常规的分离、纯化和表征, 这些硫炭基活化酯在冰箱中 保存 6 个月以上都不会变质. 同时, 它们在与另一分子 氨基酸的氨基进行氨解时反应迅速且高效. 因此, 它们 可以作为理想的固相多肽合成砌块. 我们尝试将氨基酸 的硫羰基活化酯用于固相多肽合成中引入硫肽键 ${ }^{[59]}$, 目前除了组氨酸, 其他 19 种天然氨基酸的硫羰基活化 酯都可以在固相多肽合成中高效地转化为目标产物, 利 用该方法还可以在固相多肽合成中精准地引入多个连
续的硫代酰胺键，解决了硫代多肽和硫代蛋白质研究领 域中研究对象难以获得的瓶颈问题(Scheme 9).

\section{6 炔酰胺介导的硫羰基酯的合成}

作为酯的硫代羰基类似物，硫羰基酯具有独特的物 理和化学性质, 因此, 常被作为重要的有机合成中间体 应用于各种官能团的转化 ${ }^{[60]}$. 虽然硫羰基酯具有相当 大的应用潜力 ${ }^{[61]}$ ，但是受合成方法的影响，其应用范围 还比较局限. 因此, 开发新型的硫羰基酯的高效合成方 法具有重要的意义.

基于硫代酰胺的合成，我们设想如果炔酰胺与单硫 代羧酸选择性加成制备的 $\alpha$-硫代酰基氧烯酰胺能够与 羟基/颈基之间发生酯交换反应的话，将有望发展一种 高效合成硫羰基酯的方法. 经过系统的条件篮选，我

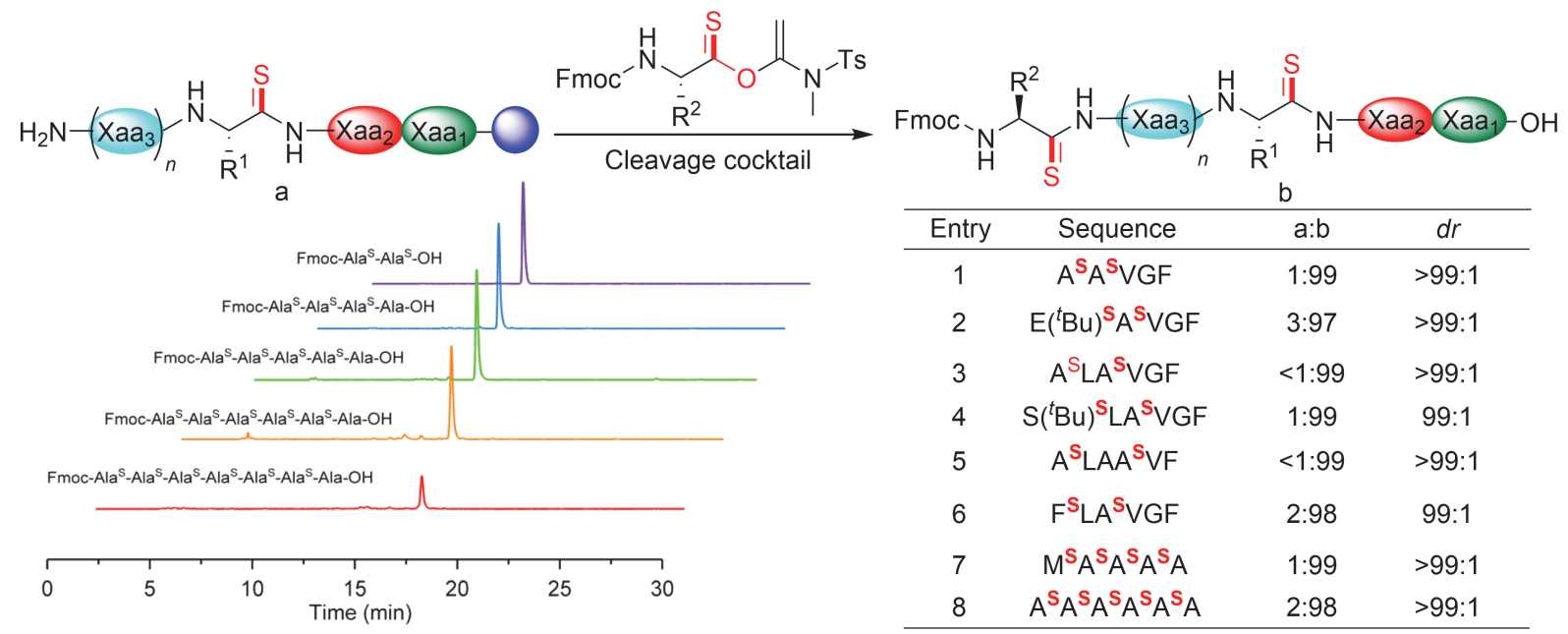

图式 9 通过固相合成在多肽主链骨架上精准引入硫代酰胺键修饰

Scheme 9 Site-specific incorporation of thioamide substitution into a peptide backbone via solid phase peptide synthesis 
们 ${ }^{[62]}$ 发现在以乙腈作为溶剂、 $\mathrm{Cs}_{2} \mathrm{CO}_{3}$ 为催化剂的条件 下，在常温下即可实现硫羰基酯的高效合成(表 10). 该 方法的底物适用范围非常广泛, 醇和酚均能顺利地反 应, 各种取代的芳香酸、杂环酸均能够适用, 活性较弱 的烷基酸以及具有较大空间位阻的底物也能顺利地进 行反应，而且对于一些多官能团的复杂底物也能够很好 的反应，并具备极好的选择性. 另外，这种方法还能够 用于二硫酯的合成，而且反应时间更快，对于大位阻的 底物也仅需几分钟即可反应完全. 此外, 半胱氨酸的侧 链巯基也能够高效地进行反应，具有修饰多肽的潜力. 不仅如此，我们还可以高效地制备硫羰基硒酯.

表 10 炔酰胺介导的硫羰基酯和二硫酯的合成 ${ }^{a}$

Table 10 Ynamide-mediated thionoester and dithioester synthesis

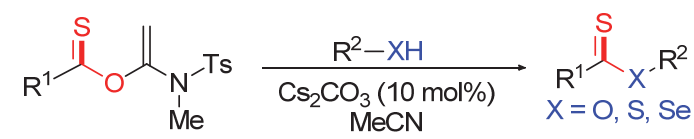<smiles>CC(=S)Sc1ccc(C(C)(C)C)cc1</smiles><smiles>C=CC=CCCCCCC(C)(C)C</smiles><smiles>CCOC(=O)C(Cc1ccccc1)NC(=O)[C@H](CSC(=S)c1ccccc1)NC(=O)c1ccccc1</smiles><smiles>S=C([Se]c1ccccc1)c1ccccc1</smiles>

${ }^{a}$ Reaction conditions: thiocarbonylester $(0.1 \mathrm{mmol})$, phenol or thiophenol $(0.2$ mmol, 2 equiv.), alcohol (2.0 mmol, 20 equiv.), $\mathrm{Cs}_{2} \mathrm{CO}_{3}$ (0.01 mmol, 0.1 equiv.), $\mathrm{CH}_{3} \mathrm{CN}(1.0 \mathrm{~mL})$, r.t., isolated yield.

\section{7 炔酰胺的合成}

炔酰胺类缩合剂在酰胺、多肽、酯、硫代酰胺、硫 代羰基酯的合成中表现出了优异的性能, 将有望发展成 为一类通用广谱的缩合试剂. 为使炔酰胺类缩合剂早日 成为真正具有工业应用价值的缩合剂, 需要发展一种成 本低廉、原料易得、操作简便的炔酰胺合成方法. 自从 1972 年 Viehe 等 ${ }^{[38]}$ 首次合成炔酰胺开始, 化学家已经发 展了一系列炔酰胺合成方法 ${ }^{[63]}$. 其中炔烃衍生物与缺 电子的仲胺偶联的方法是最为简捷直接的, 例如铜催化
的炔烃与胺的氧化偶联法 ${ }^{[64]}$ 、高价碘盐法 ${ }^{[65]}$ 以及用卤代

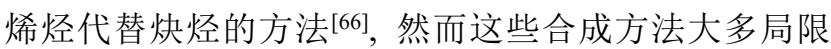
于内炔酰胺且时常伴随着严重的副反应，很多方法还涉 及到苛刻的反应条件或昂贵试剂的使用. 另外, 由于缺 乏安全高效的乙炔基试剂，端炔酰胺的合成更为繁琐， 一般都需要以预先保护的乙炔基试剂作为原料, 经过多 步反应得到内炔酰胺后，再脱除保护基才能得到端炔酰 胺. 因此, 便捷经济地合成炔酰胺, 尤其是端炔酰胺的 合成仍然是有机化学家所面临的一个挑战.

经过深入的探索，我们发展了一种以 1,1-二氯烯烃 或者 1,2-二氯烯烃作为炔烃等当体的炔酰胺合成方法, 二氯烯烃在碱性条件下与二级磺酰胺(或者酰胺)直接反 应即可得到炔酰胺[67]. 该方法操作便捷，反应条件简 单, 无需使用过渡金属催化剂. 反应底物范围广, 除了 能够制备一些常见的炔酰胺, 很多结构特殊的炔酰胺以 及炔胺也能够以较好的收率制备(表 11)。二氯烯烃策略 是当前合成炔酰胺最经济便捷的方法，而且可以大量制 备. 更重要的是以二氯乙烯为乙炔等当体，只需要通过 一步简单的操作即可实现端炔酰胺的高效合成, 避免了 传统制备端炔酰胺方法中因使用预先保护的乙炔基试 剂的保护和去保护步骤. 由于 1,1 -二氯乙烯或者 1,2-二 氯乙烯和 $N$-甲基磺酰胺都是廉价易得的大宗化工原料, 相信通过后续的深入研究，有望实现端炔酰胺的工业化 规模制备.

表 11 一锅法合成炔酰胺 ${ }^{a}$

Table 11 A robust one-step approach to ynamides
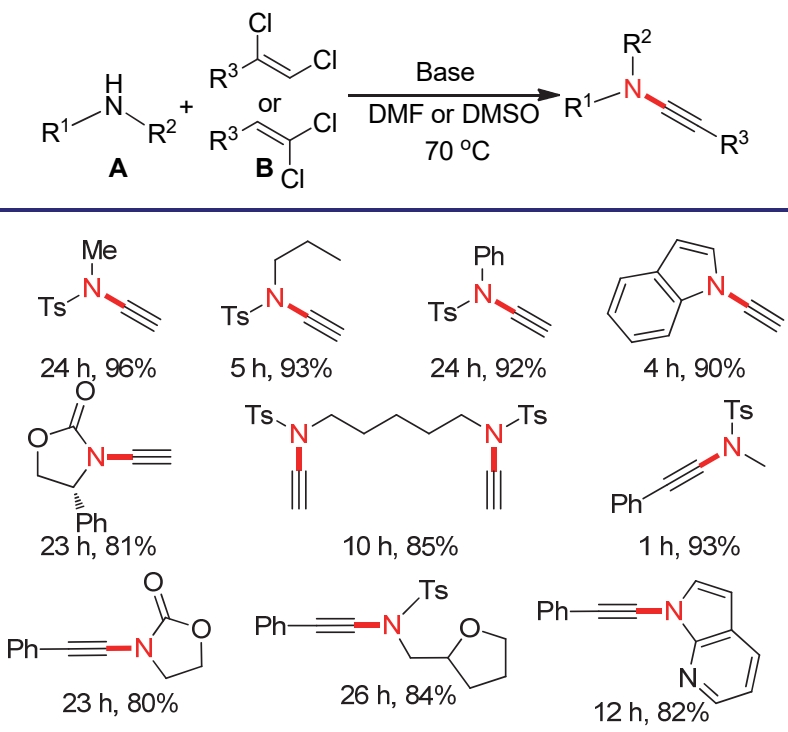

${ }^{a}$ Reaction conditions: A $(0.2 \mathrm{mmol}), \mathbf{B}(0.4 \mathrm{mmol})$, and $\mathrm{NaH}$ or $\mathrm{Cs}_{2} \mathrm{CO}_{3}(5.0$ equiv.) in DMSO or DMF $(1.0 \mathrm{~mL})$ at $70{ }^{\circ} \mathrm{C}$. isolated yield

\section{8 总结与展望}

我们设计发展了炔酰胺类缩合剂，炔酰胺通过与羧 
酸的加成反应来形成烯基活化酯，从而达到活化羧酸的 目的. 在一级或二级胺的作用下, 该类烯基活化酯能够 顺利发生氨解反应而得到相应的酰胺. 羧酸的活化与后 续的氨解都可以在温和的条件下自发进行, 从而提供了 一种构建酰胺键的便捷方法. 同时, 在酸或者碱催化剂 的存在下，该类活化酯还能够发生酯交换反应，实现了 炔酰胺介导的大环内酯化反应以及分子间酯化反应 ${ }^{[68]}$. 炔酰胺缩合剂除了能够用于普通酰胺与酯的形成, 还能 够用于肽键的形成, 其最大的优点是不会诱发羧酸 $\alpha$-位 手性中心的外消旋化. 除此之外, 炔酰胺还能够与单硫 代羧酸发生选择性的加成反应得到硫羰基活化酯, 该硫 羰基活化酯可以顺利地用于硫代酰胺以及硫羰基酯的 高效合成. 更重要的是 $\alpha$-氨基酸的硫羰基酯可以用来在 多肽主链骨架上精准、高效、无外消旋化地引入硫代酰 胺化修饰, 解决了制约硫肽键修饰在多肽与蛋白质化学 生物学研究中应用的瓶颈问题. 尽管炔酰胺类缩合剂在 促成酰胺键与酯键形成中已经表现出了优异的性能, 有 望成为一种广谱通用的缩合试剂, 但是仍然存在一些问 题和挑战. 例如, 炔酰胺类缩合剂在促成肽键形成时的 反应较慢, 影响了其在固相多肽合成中的应用. 如何发 展更加高效的炔酰胺缩合剂并将其用于固相多肽合成 是我们将来研究的重点. 我们希望通过后续的深入研 究, 进一步提升炔酰胺类缩合剂的性能并拓展其应用范 围, 使其早日成为一种真正具有工业应用价值的缩合 剂.

\section{作者简介}

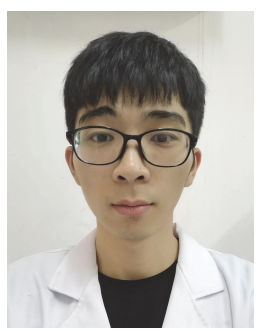

刘涛, 2017 年毕业于江西农业大学理学院, 2018 年 进入江西师范大学化学化工学院有机化学专业攻读硕 士学位, 师从赵军锋教授. 主要从事多肽绿色合成方法 研究.

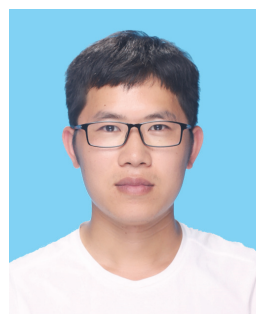

许泗林, 2015 年于许昌学院获得学士学位, 2015
2020 年在江西师范大学赵军锋教授课题组硕博连读, 于 2020 年 7 月获得博士学位，同年 9 月进入许昌学院任 讲师. 主要研究方向为多肽的化学合成与修饰和新型苂 光探针的设计与合成.

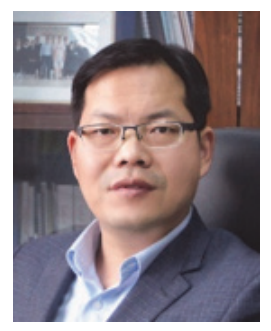

赵军锋, 教授, 洪堡学者. 2001 年和 2005 年分别于 北京师范大学和华中师范大学获学士和硕士学位. 2010 年获新加坡南洋理工大学博士学位. 2010 2013 年先后 于南洋理工大学、德国波恩大学和明斯特大学从事化学 生物学方向学的博士后研究; 2013 2014 年任香港大学 化学系助理教授 (研究); 2014 2020 年任江西师范大学 教授、博士生导师; 2021 年起, 任西北工业大学教授、 博士生导师. 课题组致力于通过发展有机化学新反应和 新试剂来解决化学生物学的前沿科学问题, 研究兴趣集 中在多肽与蛋白质的化学合成与精准修饰及其化学生 物学研究.

\section{References}

[1] Lundberg, H.; Tinnis, F.; Selander, N.; Adolfsson, H. Chem. Soc. Rev. 2014, 43, 2714.

[2] Roughley, S. D.; Jordan, A. M. J. Med. Chem. 2011, 54, 3451.

[3] (a) Valeur, E.; Bradley, M. Chem. Soc. Rev. 2009, 38, 606. (b) Han, S. Y.; Kim, Y. A. Tetrahedron 2004, 60, 2447.

(c) Montalbetti, C. A. G. N.; Falque, V. Tetrahedron 2005, 61, 10827.

(d) Hackenberger, C. P.; Schwarzer, D. Angew. Chem., Int. Ed. 2008, 47, 10030 .

(e) de Figueiredo, R. M.; Suppo, J. S.; Campagne, J. M. Chem. Rev. 2016, 116, 12029.

(f) Dunetz, J. R.; Magano, J.; Weisenburger, G. A. Org. Process Res. Dev. 2016, 20, 140.

(g) El-Faham, A.; Albericio, F. Chem. Rev. 2011, 111, 6557.

(h) Pattabiraman, V. R.; Bode, J. W. Nature 2011, 480, 471.

(i) Allen, C. L.; Williams, J. M. Chem. Soc. Rev. 2011, 40, 3405.

[4] (a) Zompra, A. A.; Galanis, A. S.; Werbitzky, O.; Albericio, F. Future Med. Chem. 2009, 1, 361 .

(b) Henninot, A.; Collins, J. C.; Nuss, J. M. J. Med. Chem. 2018, 61,1382 .

(c) Lau, J. L.; Dunn, M. K. Bioorg. Med. Chem. 2018, 26, 2700

[5] Sheehan, J. C.; Hess, G. P. J. Am. Chem. Soc. 1955, 77, 1067.

[6] Benoiton, N. L.; Chen, F. M. F. J. Chem. Soc., Chem. Commun. 1981, 543.

[7] Sheehan, J.; Cruickshank, P.; Boshart, G. J. Org. Chem. 1961, 26, 2525.

[8] Coste, J.; Le-Nguyen, D.; Castro, B. Tetrahedron Lett. 1990, 31, 205.

[9] Carpino, L. A.; El-Faham, A.; Albericio, F. Tetrahedron Lett. 1994 35, 2279.

[10] Dourtoglou, V.; Ziegler, J.-C.; Gross, B. Tetrahedron Lett. 1978, 19 , 1269. 
[11] Marder, O.; Shvo, Y.; Albericio, F. Chim. Oggi 2002, 20, 37.

[12] (a) Wehrstedt, K. D.; Wandrey, P. A.; Heitkamp, D. J. Hazard. Mater. 2005, 126, 1.

(b) Malow, M.; Wehrstedt, K. D.; Neuenfeld, S. Tetrahedron Lett. 2007, 48, 1233.

[13] Subiros-Funosas, R.; Prohens, R.; Barbas, R.; El-Faham, A.; Albericio, F. Chem.-Eur. J. 2009, 15, 9394.

[14] Sperry, J. B.; Minteer, C. J.; Tao, J. Y.; Johnson, R.; Duzguner, R.; Hawksworth, M.; Oke, S.; Richardson, P. F.; Barnhart, R.; Bill, D. R.; Giusto, R. A.; Weaver, J. D. Org. Process Res. Dev. 2018, 22, 1262 .

[15] (a) El-Faham, A.; Subiros Funosas, R.; Prohens, R.; Albericio, F. Chem.-Eur. J. 2009, 15, 9404

(b) Subiros-Funosas, R.; Acosta, G. A.; El-Faham, A.; Albericio, F. Tetrahedron Lett. 2009, 50, 6200.

[16] Belleau, B.; Malek, G. J. Am. Chem. Soc. 1968, 90, 1651.

[17] Paul, R.; Anderson, G. W. J. Am. Chem. Soc. 1960, 82, 4596.

[18] Kaminski, Z. J.; Kolesinska, B.; Kolesinska, J.; Sabatino, G.; Chelli, M.; Rovero, P.; Blaszczyk, M.; Glowka, M. L.; Papini, A. M. J. Am. Chem. Soc. 2005, 127, 16912.

[19] Gong, Y. T.; Du, Y. C.; Huang, W. D.; Chen, C. Q.; Ge, L. T.; Hu, S, Q.; Niu, J. Y.; Xu, J. C.; Zhang, W. J.; Chen, L. L.; Li, H. X.; Wang, Y.; Lu, D. P.; Ji, A. X.; Li, C. X.; Shi, B. T.; Ye, Y. H.; Tang, K. L.; Xing, Q. Y. Chin. Sci. Bull. 1965, 16, 941 (in Chinese).

(龚岳亭, 杜雨苍, 黄惟德, 陈常庆, 葛麟俊, 胡世全, 蒋荣庆, 朱尚权, 钮经义, 徐杰诚, 张伟君, 陈玲玲, 李鸿绪, 汪猷, 陆德 培, 季爱雪, 李崇熙, 施溥涛, 叶蕴华, 汤卡罗, 邢其毅, 科学通 报, 1965, 16, 941.)

[20] (a) Li, P.; Xu, J. C. Tetrahedron Lett. 1999, 40, 3605.

(b) Li, P.; Xu, J. C. Tetrahedron 2000, 56, 4437. (c) Li, P.; Xu, J. C. J. Pept. Res. 2001, 58, 129.

[21] Hamuro, Y.; Scialdone, M. A.; DeGrado, W. F. J. Am. Chem. Soc. 1999, 121, 1636.

[22] (a) Zheng, J. S.; Tang, S.; Huang, Y. C.; Liu, L. Acc. Chem. Res. 2013, 46, 2475.

(b) Fang, G. M.; Li, Y. M.; Shen, F.; Huang, Y. C.; Li, J. B.; Lin, Y.; Cui, H. K.; Liu, L. Angew. Chem., Int. Ed. 2011, 50, 7645.

(c) Fang, G.-M.; Wang, J.-X.; Liu, L. Angew. Chem., Int. Ed. 2012, $51,10347$.

(d) Li, J. B.; Tang, S.; Zheng, J. S.; Tian, C. L.; Liu, L. Acc. Chem. Res. 2017, 50, 1143 .

(e) Zhang, B.; Deng, Q.; Zuo, C.; Yan, B.; Zuo, C.; Cao, X. X.; Zhu, T. F.; Zheng, J. S.; Liu, L. Angew. Chem., Int. Ed. 2019, 58, 12231.

[23] (a) Zhang, Y.; Xu, C.; Lam, H. Y.; Lee, C. L.; Li, X. Proc. Natl. Acad. Sci. U. S. A. 2013, 110, 6657.

(b) Li, X.; Lam, H. Y.; Zhang, Y.; Chan, C. K. Org. Lett. 2010, 12, 1724.

(c) Wong, C. T. T.; Lam, H. Y.; Song, T.; Chen, G.; Li, X. Angew. Chem., Int. Ed. 2013, 52, 10212.

(d) Lee, C. L.; Liu, H.; Wong, C. T. T.; Chow, H. Y.; Li, X. J. Am. Chem. Soc. 2016, 138, 10477.

(e) Liu, H.; Li, X. Acc. Chem. Res. 2018, 51, 1643.

[24] (a) Cai, H.; Chen, M.-S.; Sun, Z.-Y.; Zhao, Y.-F.; Kunz, H.; Li, Y.-M. Angew. Chem. Int. Ed. 2013, 52, 6106.

(b) Cai, H.; Sun, Z. Y.; Chen, M. S.; Zhao, Y. F.; Kunz, H.; Li, Y. M. Angew. Chem., Int. Ed. 2014, 53, 1699.

(c) Huang, Z. H.; Shi, L.; Ma, J. W.; Sun, Z. Y.; Cai, H.; Chen, Y. X.; Zhao, Y. F.; Li, Y. M. J. Am. Chem. Soc. 2012, 134, 8730.

(d) He, Y. H.; Li, Y. M.; Chen, Y. X. Talanta 2016, 150, 340.

(e) Zhang, S. Y.; Sperlich, B.; Li, F. Y.; Al-Ayoubi, S.; Chen, H. X.; Zhao, Y. F.; Li, Y. M.; Weise, K.; Winter, R.; Chen, Y. X. $A C S$ Chem. Biol. 2017, 12, 1703.

[25] (a) Gui, Y.; Qiu, L.; Li, Y.; Li, H.; Dong, S. J. Am. Chem. Soc. 2016, 138,4890 .

(b) Chen, X.; Ye, F.; Luo, X.; Liu, X.; Zhao, J.; Wang, S.; Zhou, Q.; Chen, G.; Wang, P. J. Am. Chem. Soc. 2019, 141, 18230.

(c) Zhang, X.; Lu, G.; Sun, M.; Mahankali, M.; Ma, Y.; Zhang, M.;
Hua, W.; Hu, Y.; Wang, Q.; Chen, J.; He, G.; Qi, X.; Shen, W.; Liu, P.; Chen, G. Nat. Chem. 2018, 10, 540.

(d) Li, B.; Li, X.; Han, B.; Chen, Z.; Zhang, X.; He, G.; Chen, G. J. Am. Chem. Soc. 2019, 141, 9401.

(e) Lu, S.; Wu, Y.; Li, J.; Meng, X.; Hu, C.; Zhao, Y.; Wu, C. J. Am. Chem. Soc. 2020, 142, 16285.

(f) Yin, Y.; Fei, Q.; Liu, W.; Li, Z.; Suga, H.; Wu, C. Angew. Chem., Int. Ed. 2019, 58, 4880.

(g) Zheng, Y.; Meng, X.; Wu, Y.; Zhao, Y.; Wu, C. Chem. Sci. 2018, 9, 569 .

(h) Zhan, B. B.; Li, Y.; Xu, J. W.; Nie, X. L.; Fan, J.; Jin, L.; Shi, B. F. Angew. Chem., Int. Ed. 2018, 57, 5858 .

(i) Zhan, B.-B.; Fan, J.; Jin, L.; Shi, B.-F. ACS Catal. 2019, 9, 3298.

(j) Wang, C.; Guo, M.; Qi, R.; Shang, Q.; Liu, Q.; Wang, S.; Zhao

L.; Wang, R.; Xu, Z. Angew. Chem., Int. Ed. 2018, 57, 15841.

(k) Wang, C.; Qi, R.; Xue, H.; Shen, Y.; Chang, M.; Chen, Y.; Wang, R.; Xu, Z. Angew. Chem., Int. Ed. 2020, 59, 7461.

(1) Bai, Z.; Cai, C.; Yu, Z.; Wang, H. Angew. Chem., Int. Ed. 2018, 57,13912

(m) Tang, J.; Chen, H.; He, Y.; Sheng, W.; Bai, Q.; Wang, H. Nat. Commun. 2018, 9, 3383.

(n) Yin, H.; Zheng, M.; Chen, H.; Wang, S.; Zhou, Q.; Zhang, Q.; Wang, P. J. Am. Chem. Soc. 2020, 142, 14201.

(o) Wang, C.; Guo, M.; Qi, R.; Shang, Q.; Liu, Q.; Wang, S.; Zhao, L.; Wang, R.; Xu, Z., Angew. Chem., Int. Ed. 2018, 57, 15841.

(p) Wang, C.; Qi, R.; Xue, H.; Shen, Y.; Chang, M.; Chen, Y.; Wang, R.; Xu, Z. Angew. Chem., Int. Ed. 2020, 59, 7461.

[26] (a) Li, H.; Chao, J.; Hasan, J.; Tian, G.; Jin, Y.; Zhang, Z.; Qin, C. J. Org. Chem. 2020, 85, 6271.

(b) Li, H. D.; Chao, J.; Tian, G.; Hasan, J.; Jin, Y. T.; Zhang, Z. X.; Qin, C. G. Org. Chem. Front. 2020, 7, 689.

(c) Li, H.; Chao, J.; Zhang, Z.; Tian, G.; Li, J.; Chang, N.; Qin, C. Org. Lett. 2020, 22, 3323.

[27] (a) Tian, J.; Gao, W.-C.; Zhou, D.-M.; Zhang, C. Org. Lett. 2012, 14, 3020 .

(b) Zhang, C.; Liu, S.-S.; Sun, B.; Tian, J. Org. Lett. 2015, 17, 4106.

[28] (a) Zhang, B.; Li, Y.; Shi, W.; Wang, T.; Zhang, F.; Liu, L. Chem. Res. Chin. Univ. 2020, 36, 733.

(b) Dawson, P.; Muir, T.; Clark-Lewis, I.; Kent, S. Science 1994, 266,776 .

(c) Kent, S. B. Chem. Soc. Rev. 2009, 38, 338.

(d) Jin, K.; Li, X. Chem.-Eur. J. 2018, 24, 17397.

(e) Zheng, J.-S.; Tang, S.; Huang, Y.-C.; Liu, L. Acc. Chem. Res. 2013, 46, 2475.

(f) Rohde, H.; Seitz, O. Biopolymers 2010, 94, 551.

(g) Yang, R.; Pasunooti, K. K.; Li, F.; Liu, X. W.; Liu, C. F. J. Am. Chem. Soc. 2009, 131, 13592.

(h) Agouridas, V.; El Mahdi, O.; Diemer, V.; Cargoët, M.; Monbaliu, J.-C. M.; Melnyk, O. Chem. Rev. 2019, 119, 7328.

(i) Yang, J.; Zhao, J. Sci. China: Chem. 2018, 61, 97.

[29] Merrifield, R. B. J. Am. Chem. Soc. 1963, 85, 2149.

[30] (a) Coin, I.; Beyermann, M.; Bienert, M. Nat. Protoc. 2007, 2, 3247.

(b) Zheng, J.-S.; Yu, M.; Qi, Y.-K.; Tang, S.; Shen, F.; Wang, Z.-P.; Xiao, L.; Zhang, L.; Tian, C.-L.; Liu, L. J. Am. Chem. Soc. 2014, 136, 3695 .

[31] Constable, D. J. C.; Dunn, P. J.; Hayler, J. D.; Humphrey, G. R.; Leazer, J. J. L.; Linderman, R. J.; Lorenz, K.; Manley, J.; Pearlman, B. A.; Wells, A.; Zaks, A.; Zhang, T. Y. Green Chem. 2007, 9, 411.

[32] (a) Wang, T.; Yuan, L.; Zhao, Z. G.; Shao, A. L.; Gao, M.; Huang, Y. F.; Xiong, F.; Zhang, H. L.; Zhao, J. F. Green Chem. 2015, 17, 2741.

(b) Zhao, Z. G.; Wang, T.; Yuan, L.; Hu, X.; Xiong, F.; Zhao, J. F. Adv. Synth. Catal. 2015, 357, 2566.

(c) Zhao, Z. G.; Wang, T.; Yuan, L.; Jia, X. W.; Zhao, J. F. RSC Adv. 2015, 5, 75386.

[33] Arens, J. F. Recl. Trav. Chim. Pays-Bas 1955, 74, 769.

[34] (a) Kita, Y.; Akai, S.; Ajimura, N.; Yoshigi, M.; Tsugoshi, T.; Ya- 
suda, H.; Tamura, Y. J. Org. Chem. 1986, 51, 4150.

(b) Krause, T.; Baader, S.; Erb, B.; Goossen, L. J. Nat. Commun. 2016, 7, 11732 .

(c) Wasserman, H. H.; Wharton, P. S. Tetrahedron 1958, 3, 321.

(d) Kita, Y.; Maeda, H.; Omori, K.; Okuno, T.; Tamura, Y. Synlett 1993, 273.

(e) Wasserman, H. H.; Wharton, P. S. J. Am. Chem. Soc. 1960, 82, 661

[35] Buijle, R.; Viehe, H. G. Angew. Chem., Int. Ed. 1964, 3, 582.

[36] Gais, H.-J. Angew. Chem., Int. Ed. 1978, 17, 597.

[37] Lienhard, U.; Fahrni, H.-P.; Neuenschwander, M. Helv. Chim. Acta. 1978, 61, 1609 .

[38] Viehe, H. G.; van Vyve, T.; Janousek, Z. Angew. Chem., Int. Ed. 1972, 11, 916 .

[39] (a) Huang, B.; Zeng, L.; Shen, Y.; Cui, S. Angew. Chem., Int. Ed. $\mathbf{2 0 1 7}, 56,4565$.

(b) Zeng, L.; Lin, Y.; Li, J.; Sajiki, H.; Xie, H.; Cui, S. Nat. Commun. 2020, 11, 5639.

(c) Zeng, L.; Cui, S. Chin. J. Org. Chem. 2020, 40, 2353 (in Chinese). (曾林伟, 崔孙良, 有机化学, 2020, 40, 2353.)

(d) Shu, C.; Wang, Y. H.; Zhou, B.; Li, X. L.; Ping, Y. F.; Lu, X.; Ye, L. W. J. Am. Chem. Soc. 2015, 137, 9567.

(e) Hong, F. L.; Chen, Y. B.; Ye, S. H.; Zhu, G. Y.; Zhu, X. Q.; Lu, X.; Liu, R. S.; Ye, L. W. J. Am. Chem. Soc. 2020, 142, 7618.

(f) Hong, F. L.; Ye, L. W. Acc. Chem. Res. 2020, 53, 2003.

(g) Wang, Z. S.; Chen, Y. B.; Zhang, H. W.; Sun, Z.; Zhu, C.; Ye, L. W. J. Am. Chem. Soc. 2020, 142, 3636.

(h) Ye, L. W.; Zhu, X. Q.; Sahani, R. L.; Xu, Y.; Qian, P. C.; Liu, R. S. Chem. Rev. 2020, DOI: 10.1021/acs.chemrev.0c00348.

[40] (a) Evano, G.; Coste, A.; Jouvin, K. Angew. Chem., Int. Ed. 2010, 49, 2840.

(b) DeKorver, K. A.; Li, H.; Lohse, A. G.; Hayashi, R.; Lu, Z.; Zhang, Y.; Hsung, R. P. Chem. Rev. 2010, 110, 5064.

(c) Chen, Y. B.; Qian, P. C.; Ye, L. W. Chem. Soc. Rev. 2020, 49, 8897.

[41] Smith, D. L.; Goundry, W. R.; Lam, H. W. Chem. Commun. 2012, 48,1505 .

[42] Xu, S.; Liu, J.; Hu, D.; Bi, X. Green Chem. 2015, 17, 184.

[43] Hu, L.; Xu, S.; Zhao, Z.; Yang, Y.; Peng, Z.; Yang, M.; Wang, C.; Zhao, J. J. Am. Chem. Soc. 2016, 138, 13135.

[44] Chang, H. N.; Liu, B. Y.; Qi, Y. K.; Zhou, Y.; Chen, Y. P.; Pan, K. M.; Li, W. W.; Zhou, X. M.; Ma, W. W.; Fu, C. Y.; Qi, Y. M.; Liu, L.; Gao, Y. F. Angew. Chem., Int. Ed. 2015, 54, 11760.

[45] (a) Neises, B.; Steglich, W. Angew. Chem., Int. Ed. 1978, 17, 522. (b) Fischer, E.; Speier, A. Ber. Dtsch. Chem. Ges. 1895, 28, 3252. (c) Tu, Y.; Yuan, L.; Wang, T.; Wang, C.; Ke, J.; Zhao, J. J. Org. Chem. 2017, 82, 4970.

(d) De Sarkar, S.; Grimme, S.; Studer, A. J. Am. Chem. Soc. 2010, 132,1190

(e) Ogawa, H.; Chihara, T.; Taya, K. J. Am. Chem. Soc. 1985, 107, 1365 .

(f) Xu, T.; Alper, H. J. Am. Chem. Soc. 2014, 136, 16970.

(g) Ishihara, K.; Ohara, S.; Yamamoto, H. Science 2000, 290, 1140.

[46] Wang, X.; Yang, Y.; Zhao, Y.; Wang, S.; Hu, W.; Li, J.; Wang, Z.; Yang, F.; Zhao, J. J. Org. Chem. 2020, 85, 6188.

[47] Parenty, A.; Moreau, X.; Niel, G.; Campagne, J. M. Chem. Rev. 2013, 113, PR1
[48] Inanaga, J.; Hirata, K.; Saeki, H.; Katsuki, T.; Yamaguchi, M. Bull. Chem. Soc. Jpn. 1979, 52, 1989.

[49] (a) Furstner, A.; Bouchez, L. C.; Funel, J. A.; Liepins, V.; Poree, F. H.; Gilmour, R.; Beaufils, F.; Laurich, D.; Tamiya, M. Angew. Chem., Int. Ed. 2007, 46, 9265.

(b) Furstner, A.; Aissa, C.; Chevrier, C.; Teply, F.; Nevado, C.; Tremblay, M. Angew. Chem., Int. Ed. 2006, 45, 5832. (c) Zhuo, C. X.; Furstner, A. Angew. Chem., Int. Ed. 2016, 55, 6051.

[50] Yang, M.; Wang, X. W.; Zhao, J. F. ACS Catal. 2020, 10, 5230.

[51] Cochrane, J. R.; Yoon, D. H.; McErlean, C. S.; Jolliffe, K. A. Beilstein J. Org. Chem. 2012, 8, 1344.

[52] (a) Mahanta, N.; Szantai-Kis, D. M.; Petersson, E. J.; Mitchell, D. A. ACS Chem. Biol. 2019, 14, 142.

(b) Müller, M. M. Biochemistry 2018, 57, 177.

[53] (a) Clausen, K.; Spatola, A. F.; Lemieux, C.; Schiller, P. W.; Lawesson, S. O. Biochem. Biophys. Res. Commun. 1984, 120, 305.

(b) Seebach, D.; Ko, S. Y.; Kessler, H.; Köck, M.; Reggelin, M.; Schmieder, P.; Walkinshaw, M. D.; Bölsterli, J. J.; Bevec, D. Helv. Chim. Acta 1991, 74, 1953.

(c) Yao, S.; Zutshi, R.; Chmielewski, J. Bioorg. Med. Chem. Lett. 1998, 8, 699 .

[54] Szantai-Kis, D.; Walters, C.; Barrett, T.; Hoang, E.; Petersson, E. Synlett 2017, 28, 1789.

[55] Kato, S.; Akada, W.; Mizuta, M.; Ishii, Y. Bull. Chem. Soc. Jpn. 1973, 46, 244.

[56] (a) Hoeeg-Jensen, T.; Olsen, C. E.; Holm, A. J. Org. Chem. 1994, $59,1257$.

(b) Høeg-Jensen, T.; Havsteen Jakobsen, M.; Olsen, C. E.; Holm, A. Tetrahedron Lett. 1991, 32, 7617.

[57] Yang, J.; Wang, C.; Xu, S.; Zhao, J. Angew. Chem., Int. Ed. 2019, $58,1382$.

[58] Mukherjee, S.; Verma, H.; Chatterjee, J. Org. Lett. 2015, 17, 3150.

[59] Yang, J.; Wang, C.; Yao, C.; Chen, C.; Hu, Y.; He, G.; Zhao, J. J. Org. Chem. 2020, 85, 1484.

[60] Jones, B. A.; Bradshaw, J. S. Chem. Rev. 1984, 84, 17.

[61] (a) Cerda, M. M.; Newton, T. D.; Zhao, Y.; Collins, B. K.; Hendon, C. H.; Pluth, M. D. Chem. Sci. 2019, 10, 1773.

(b) Cerda, M. M.; Zhao, Y.; Pluth, M. D. J. Am. Chem. Soc. 2018, $140,12574$.

[62] Yao, C.; Yang, J.; Lu, X.; Zhang, S.; Zhao, J. Org. Lett. 2020, 22, 6628.

[63] Evano, G.; Blanchard, N.; Compain, G.; Coste, A.; Demmer, C. S.; Gati, W.; Guissart, C.; Heimburger, J.; Henry, N.; Jouvin, K.; Karthikeyan, G.; Laouiti, A.; Lecomte, M.; Martin-Mingot, A.; Metayer, B.; Michelet, B.; Nitelet, A.; Theunissen, C.; Thibaudeau, S.; Wang, J. J.; Zarca, M.; Zhang, C. Y. Chem. Lett. 2016, 45, 574.

[64] Hamada, T.; Ye, X.; Stahl, S. S. J. Am. Chem. Soc. 2008, 130, 833.

[65] (a) Witulski, B.; Stengel, T. Angew. Chem., Int. Ed. 1998, 37, 489. (b) Rainier, J. D.; Imbriglio, J. E. Org. Lett. 1999, 1, 2037. (c) Witulski, B.; Lumtscher, J.; Bergstrasser, U. Synlett 2003, 708.

[66] Coste, A.; Karthikeyan, G.; Couty, F.; Evano, G. Angew. Chem., Int. Ed. 2009, 48, 4381.

[67] (a) Tu, Y.; Zeng, X.; Wang, H.; Zhao, J. Org. Lett. 2018, 20, 280. (b) Zeng, X.; Tu, Y.; Zhang, Z.; You, C.; Wu, J.; Ye, Z.; Zhao, J. J. Org. Chem. 2019, 84, 4458.

[68] Song, Q.; Kong, L.; Zhu, L.; Hong, R.; Huang, S. H. Chin. J. Chem. 2020, 39, 1022 . 